\title{
Consolidating the Covid Debt
}

\author{
Christian Keuschnigg, Julian Johs, and Jacob Stevens* \\ University of St. Gallen, FGN-HSG
}

December 20, 2021

\begin{abstract}
One of the main functions of public debt is to smooth taxes and spending over time. In the Covid crisis, the Maastricht deficit restrictions were temporarily suspended to allow for large temporary deficits. As recovery sets in, countries are confronted with the task of consolidating the Covid debt. This paper explores a fiscal consolidation strategy combined with growth enhancing tax and expenditure reform. We quantitatively illustrate that this reform based strategy, by reaping substantial efficiency gains and inducing strong growth, eliminates the Covid debt, protects per capita social entitlements and yet avoids increasing tax rates. With slow consolidation, marginal tax rates are reduced right from the beginning.
\end{abstract}

JEL classification: E62, H24, H25, H55, H63.

Keywords: Covid debt, fiscal consolidation, tax and expenditure reform, growth.

${ }^{*}$ Keuschnigg (corresponding author), University of St. Gallen, Christian.Keuschnigg@unisg.ch;

Johs: Business University of Vienna and WPZ Research, Julian.Johs@wpz-research.com; Stevens: University of St Andrews, jrs28@st-andrews.ac.uk. We appreciate financial support by the Austrian National Bank (OeNB Jubiläumsfonds Projekt Nr. 18305) and by the Austrian Ministry of Finance. We are grateful for constructive comments by Martin Ruf and seminar participants at the Universities of St. Gallen and Tuebingen. 


\section{Introduction}

The Covid crisis is a classic example for one of the main functions of public debt, to smooth taxes and spending over time and to redistribute the fiscal costs of catastrophic events across generations. To this end, the Maastricht deficit restrictions were temporarily suspended to allow the pandemic costs go into debt. In Europe, the debt to GDP ratio exploded by between 8 to $17 \%$ of 2019 GDP as a result of additional deficits while, in the U.S., public debt soared by more than 30\% of 2019 GDP (see Figure 1). As recovery sets in, countries need to stabilize public budgets and consolidate the Covid debt. The present analysis doesn't explain the need for consolidation itself but rather takes it as given. Possible arguments could be institutional constraints such as the Maastricht treaty, the need to recover fiscal space for future crisis intervention, taking precautionary action to avoid speculative attacks on sovereign debt, or protecting against rising interest rates.

At least in the short-run, consolidating fiscal budgets requires a combination of spending cuts and tax increases. However, spending cuts and tax increases can take many forms with potentially very different consequences for growth and distribution. In addition, a given debt to GDP target depends not only on the level of debt, but also on the level of GDP. This paper explores alternatives for fiscal consolidation of the Covid debt. Is it possible to cut back debt to GDP ratios by a fiscal strategy of growth enhancing tax and expenditure reform? Can debt to GDP ratios be reduced without raising marginal tax rates and cutting entitlements per capita? How can governments achieve an equitable inter-generational burden sharing?

The present paper explores alternatives for consolidating the Covid debt, taking Austria as an example. The size of the problem and the range of potential reforms are necessarily country specific but the chosen scenarios should be informative for other countries as well. For quantitative results, we use an estimated DSGE model with a detailed mod-

eling of the public sector. Following Bayer et al. (2020), we first mimick the effects of the Covid crisis with a cumulative output loss of $15.7 \%$ of pre crisis GDP over 9 quar- 


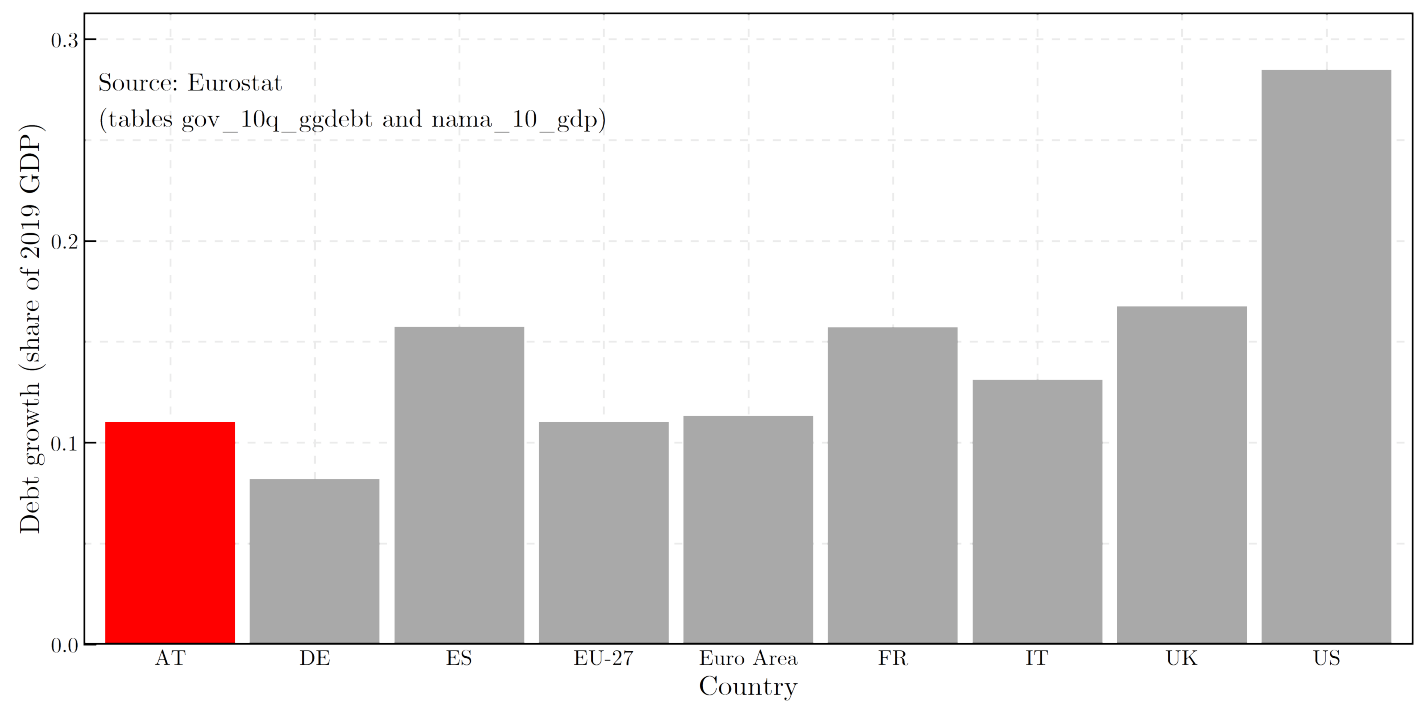

Figure 1: Covid Debt in \% of 2019 GDP

ters and a cumulative increase in public debt equal to $13.4 \%$ of pre crisis GDP. ${ }^{1}$ As a base case scenario, we assume the government to stabilize the debt to GDP ratio at the permanently higher post crisis level and to follow a passive strategy of scaling up all tax rates to generate the required primary fiscal surpluses. Past experience indeed shows that most governments mainly rely on tax based consolidation. Then we implement a series of alternative consolidation strategies to bring back the debt to GDP ratio to the pre crisis level. $^{2}$ We implement a debt rule in the spirit of the Maastricht criteria that targets a slow reduction in the debt to GDP ratio, again following a passive strategy of raising all tax rates. The picture is rather unfavorable since tax rates need to increase quite significantly in the early adjustment phase to generate the required primary surpluses, thereby harming present generations and delaying the recovery.

The next part of the paper explores the possibilities of fundamental, efficiency improving fiscal reform that strengthens growth and much reduces or even avoids the negative

\footnotetext{
${ }^{1}$ The model cannot exactly reproduce actual numbers which report a $12.5 \%$ output loss and a $19.6 \%$ increase in debt.

${ }^{2}$ The pre crisis GDP ratio exceeds the Maastricht target of $60 \%$ of GDP. Since historic debt stems from other sources, we do not consider any further reduction beyond consolidating the Covid debt.
} 
consequences of consolidation. Can a country succeed to grow out of high public debt by keeping debt levels largely constant and letting GDP growth reduce the debt to GDP ratio? Clearly, there is a large range of possible reforms. ${ }^{3}$ We pick out four alternatives which promise large efficiency gains and budget savings and thereby illustrate the general point that growing out of high debt might be possible.

The first element is VAT (value added tax) reform. In most countries, the VAT is complicated and a partly growth reducing tax. To a substantial degree, VAT exemptions lead to costly taxation of investment and intermediate inputs rather than consumption. Reduced rates are ill targeted and therefore expensive ways to redistribute and to support 'deserving' industries, with better and more targeted instruments available to the government. Eliminating exemptions restores the consumption tax character of the VAT and contributes to competitiveness and growth. Depending on the degree of compensation of 'losers', such reform is also raising the yield of the tax at given rates, thereby reducing somewhat the need to raise distortive marginal tax rates. Our scenario is related to the literature on the benefits of 'fiscal devaluations' to restore competitiveness and growth in the Eurozone (e.g. Farhi et al., 2014; Engler et al., 2017). This literature suggests raising VAT taxes and reducing payroll taxes to reduce prices when external devaluations are not possible. Our scenario achieves the same result by an efficiency improving VAT reform without raising the general VAT rate. ${ }^{4}$

The second pillar of the strategy is corporate tax reform by introducing an allowance for corporate equity (ACE). Such reform entails a strong growth effect by reducing the effective marginal tax rate on investment to zero and could substantially +increase GDP by several percentage points (see, e.g., (Benzell et al., 2017) and (Altig et al., 2001)). In addition, it eliminates a major tax bias in favor of debt and thereby strengthens economic resilience. For these reasons, the majority of fundamental tax reform proposals such as

\footnotetext{
${ }^{3}$ De Mooij et al. (2021) discuss many alternative options that should stimulate inclusive growth.

${ }^{4}$ The macro literature arguably paints a too positive picture of fiscal devaluation by treating the VAT as a pure consumption tax which it isn't in reality due to exemptions. In any case, it also appears preferable to make the VAT a less distorting tax before raising the tax rate.
} 
the Mirrlees review (Institute for Fiscal Studies and Mirrlees, 2011) recommend such reform, either by introducing an ACE allowance, or moving to a cash-flow tax with full immediate deduction of investment spending. The two alternatives differ in the timing of tax revenue losses. While a cash-flow tax immediately impairs tax revenue, an ACE allowance delays budget losses since it creates deductions only when the returns to capital eventually materialize at a later date. This timing is particularly attractive when fiscal budgets are tight. By limiting ACE deductions to new equity capital created by new investment, the government can induce strong growth effects and yet limit revenue losses in the early adjustment phase. Initially, old equity is fully taxed. The tax deductible share of equity capital rises slowly over time, as growth sets in, and reaches $100 \%$ only after convergence to the new steady state equilibrium.

The third pillar of the consolidation strategy is a more rapid increase in the retirement age. Postponing retirement makes individuals pay contributions longer and consume pensions over a shorter fraction of life. In a cross-section, such reform swells the mass of tax payers and shrinks the group of pensioners. The reform yields powerful fiscal effects since it simultaneously boosts revenues from wage taxes and social security contributions and contains pension benefits. In strengthening aggregate labor supply, it also entails a strong and sustained growth effect. On the negative side, the budget savings emerge only with much delay. Protecting the rightful claims of existing pensioners and people close to retirement age requires that the reform is phased in with substantial delay. Budget savings are slow to come but long-lasting. This scenario is particularly relevant for Austria which has one of the earliest average retirement ages in Europe and heavily subsidizes the pension system with large transfers out of the general budget. Given demographic trends, raising the retirement age is the only strategy to ensure sustainability of the pension system without raising (already high) contribution rates or significantly cutting individual entitlements. The reform moves the system towards actuarial fairness and strengthens aggregate labor supply.

A fourth pillar reduces ill targeted tax deductions and cuts spending on public con- 
sumption. In practice, policy makers can choose among a multitude of alternatives. Consolidating the budget in a growth friendly way would certainly require to keep up public investment spending for basic research, education and training, fiscal R\&D incentives, and other productive infrastructure spending (including an efficient legal system). But there is probably some potential to reduce $\mathrm{X}$-inefficiencies in public spending such as eliminating wasteful subsidies and ill-targeted social spending. Speeding up digitization and other organizational reform could boost public sector productivity for a more efficient provision of public services. Cutting tax loop-holes and broadening the tax base would be another way to strengthen fiscal revenue without raising already high marginal tax rates. Tax statistics suggest that about a quarter of the total income tax base is reduced by tax deductions, many of them without a clear rationale and not systematically evaluated to see whether they achieve the stated objectives. Specifically, we assume that income tax deductions can be reduced from 25 to $20 \%$ of the wage tax base without compromising distributional and other objectives. The government could probably achieve cost savings in supplying public services worth $0.5 \%$ of GDP (reducing public consumption spending from 15 to $14.5 \%$ of GDP) without harming growth. Cutting 'unproductive' spending and strengthening the tax yield by eliminating ill-targeted tax deductions or outright tax loopholes lead to budget improvements which allow to cut highly distorting marginal tax rates and provide a further growth stimulus.

Our paper expands and innovates upon existing literature in several ways. A rigorous analysis of the proposed consolidation strategy requires a unified framework that combines (i) an overlapping generations (OLG) model with changing retirement patterns; (ii) a rich model of capital income taxation at the corporate and personal level; (iii) a stylized and tractable model of interindustry relations to capture the problems related to exemptions and reduced rates in VAT taxation; (iv) a modeling of consolidation policies in the spirit of Maastricht rules, distinguishing temporary and structural deficits; and (v) a modeling of the Covid shock that endogenously explains the emergence of the Covid debt. Although some aspects are known from separate, specialized contributions (see the literature review in the next subsection), we believe that our model is quite unique in existing DSGE 
research and allows a novel analysis of alternative consolidation strategies.

Strong growth facilitates fiscal consolidation. Based on the institutional and structural background in Austria, our results show that it might be possible to consolidate the Covid debt by 'growing out of high debt levels'. Our policy scenarios are not unique and might only loosely relate to a fully optimal policy which would be extremely difficult to characterize in the context of our rich model structure. The key idea behind the policy design is to reap unexploited efficiency gains and implement welfare improving reform that would make sense even without any need for consolidation. With strong growth, fiscal consolidation would be less painful and politically easier, if unfavorable distributional consequences can be controlled for. ${ }^{5}$ The simulations suggest that consolidation combined with fundamental policy reform in five steps, as discussed above, could boost GDP by about $11 \%$ in the long-run and reduce the tax to GDP ratio by almost 7 percentage points, compared to current trends. The increase in the debt to GDP ratio caused by the Covid crisis is reversed and brought back to the current level without cutting individual benefit entitlements or raising tax rates. Considering the entire transition period shows that tax rates could be reduced right from the beginning if fiscal consolidation proceeds very slowly and is stretched over many periods. A more ambitious strategy for a faster reduction of the Covid debt, however, must achieve higher fiscal surpluses today which reduces the gains of current generations.

Section 2 informs how the paper relates to existing research. Section 3 sets out an estimated DSGE model, with calibration and estimation choices in an Appendix. Section 4 first discusses the Covid recession and the rise in public debt, and then presents quantitative results for alternative consolidation strategies. Section 5 concludes.

\footnotetext{
${ }^{5}$ Ayaz et al. (2021), for example, study how the income tax schedule should be optimally adjusted when fiscal pressure increases. Our analysis is complementary, scales all tax rates by a common factor, and explores whether structural fiscal reform can achieve consolidation without raising tax rates and cutting per capita social entitlements.
} 


\section{A Review of Existing Research}

Our OLG model is implemented in quarterly frequency and allows for analytical aggregation of infinitely many agents into two age groups, following Gertler (1999) and, more recently, Galí (2021). In allowing a variable transition from work into retirement, we can model the macroeconomic effects of an increase in retirement age. ${ }^{6}$ Our modeling of investment and capital income taxation builds on Keuschnigg and Keuschnigg (2012) which itself goes beyond Altig et al. (2001) in modeling an ACE reform. The concept of an ACE tax was popularized by early contributions of Boadway and Bruce (1984) and Bond and Devereux (1995) and is included in the tax reform proposal of the Mirrlees review (Institute for Fiscal Studies and Mirrlees (2011)). De Mooij and Devereux (2011) compute substantial growth effects of an ACE reform. In addition, De Mooij and Devereux (2011) and, more recently, Hebous and Ruf (2017) found that the ACE tax is effective in eliminating the debt bias and can substantially improve debt equity choice. These authors also point to some practical concerns that should be taken into account when implementing an ACE reform in an international context. A novel aspect of this paper is to highlight the dynamics of an ACE reform which is particularly attractive when the fiscal budget is tight. In restricting ACE deductions to new equity capital only, the suggested ACE reform is able to avoid windfall gains to old capital and immediately strengthens investment and growth while shifting revenue losses to future periods.

The present paper contributes to research on VAT taxation in providing a stylized analysis with analytical results regarding the effects of VAT on intermediate input and investment goods prices. The problem arises with exemptions where tax favored sectors such as health and educational sectors, banking and insurance services, or real estate and housing transactions are not subject to VAT but are also not allowed to recover VAT on inputs. ${ }^{7}$ Early calculations of Gottfried and Wiegard (1991), using a static general

\footnotetext{
${ }^{6}$ See Jaag et al. (2010) for an application to pension reform with more detailed demographics.

${ }^{7}$ An additional difficulty is the exemption of small businesses for administrative reasons and the appropriate choice of the VAT threshold, see Liu et al. (2021) for a recent analysis.
} 
equilibrium model with detailed intersectoral linkages, show that only $63 \%$ of VAT revenue was on consumption while $21 \%$ rested on intermediate inputs and $16 \%$ on investment. While the efficiency costs of exemptions due to distortions of input choices have long been recognized, an analytically tractable macroeconomic approach was never established. The analysis shows that VAT reform works much like a productivity increase by eliminating input distortions and thereby encouraging investment and growth. Out paper thereby links to the above mentioned literature on fiscal devaluation which recommends to shift the tax burden from labor to indirect taxes to strengthen competitiveness and growth. Furthermore, reduced rates are also not an efficient distributional instrument. The static model analysis of Boeters et al. (2010) suggests that replacing differentiated VAT rates with a uniform rate has only negligible effects on redistribution.

Our paper relates to the findings of existing research on tax vs. expenditure consolidation, such as Alesina et al. (2019) and Beetsma et al. (2021). They demonstrate empirically that consolidating via reduced expenditure is more effective and less costly in terms of output than consolidation via higher taxes. They classify austerity programs using the narrative approach of Romer and Romer (2010). Specifically, Alesina et al. (2019) examine the actual implementation of the measures and find that tax-based consolidation reduces GDP by $1.75 \%$ more than expenditure-based consolidation (normalising the consolidation volume to 1\% GDP). Beetsma et al. (2021) instead look at the announcement of such measures and similarly find a difference of $1.5-2 \%$ in lost output if the consolidation is tax-based. Alesina et al. (2019) suggest several reasons for this, notably the consumption and labour supply responses and the distortion of investment incentives.

We go further by exploring ways to minimise the costs of tax-based consolidation through specific structural reforms to value added, business and personal income taxation, by considering the differential effects of spending cuts in public consumption and public investment, and by including the powerful effects of pension reform via an increase in retirement age. Beyond that, and in the spirit of the Maastricht rules, our analysis distinguishes between temporary and structural deficits where only the structural part is 
subject to the government's consolidation policy. Indeed, in March 2020, the European Council took the unprecedented step of activating the "General Escape Clause", effectively suspending the debt and deficit restrictions placed upon member nations by the Stability and Growth Pact (SGP). Referring to structural deficits, the SGP requires member states to converge on the long-run debt to GDP target of 60\% 'as quickly as possible', which is formalised by requiring reductions of at least one-twentieth of the excess debt each year. Our consolidation rule approximates this requirement, and the estimated consolidation speed comes close to it.

Finally, our paper models the emergence of Covid debt as a result of the pandemic and links to the literature on the Covid-19 crisis. This research may be loosely divided into papers which treat the pandemic as an exogenous shock (as we do), and those which endogenise the epidemiological side in a combined "DSGE-SIR" model, e.g., Kaplan et al. (2020), and Bayer et al. (2020). A core component of the DSGE-SIR literature is the negative feedback loop between labour supply and disease incidence. Higher disease incidence reduces effective labour supply through some combination of household incentives and government intervention. Reduced labour supply, in turn, slows down the disease incidence since there is less transmission in workplaces. Our focus is not on the dynamics of the Covid crisis but on the effects of debt consolidation. We thus cut out such detail and follow the literature which treats Covid-19 as an exogenous, transient shock. Two out of many examples are Caballero and Simsek (2021) and Gregory et al. (2020).

Furthermore, Covid 19 research has taken different approaches to modelling the mechanisms by which the disease affects the economy. It is exceptionally common to model an impact on labour supply such as an increased distaste for work during the pandemic (as in Krueger et al., 2020), a government-imposed constraint on household labour supply (as in Kaplan et al., 2020), or a fraction of the workforce being temporarily unable to work (as in Bayer et al., 2020). We follow this last approach which models the output loss from a pandemic as a large, temporary underutilization of labor and capital. It also allows government support to be targeted to those directly affected by the pandemic, 
rather than being applied to the unemployed in general. We believe this is the most defensible choice in a European context where the emphasis has been on targeted subsidies to those individuals and businesses most affected. The challenge of consolidating the resulting fiscal debt has generally been considered only in simplistic terms. The majority of papers simply abstracts away from government intervention (e.g., Krueger et al., 2020, and Gregory et al., 2020, amongst many others). Those papers which model government finances more explicitly consider rather mechanical consolidation rules and mainly focus on the short-run effects of the stimulus. For example, Kaplan et al. (2020) simply assume a smooth rise in long-run labour income taxes until the budget is balanced, while Bayer et al. (2020) models both revenue and expenditure as functions of the debt/GDP ratio.

\section{The Model}

We use an DSGE model of an open economy, combining overlapping generations of households and a production sector using capital, labor and intermediate inputs. The fiscal budget includes the main taxes, spending on government services, pensions and other social transfers, and accumulation of government debt. For the sake of brevity, we present only an overview. The Appendix of the paper informs about estimation and calibration of the model which is implemented in quarterly frequency. A separate technical working paper provides a complete documentation. ${ }^{8}$

\subsection{Overlapping Generations}

The household sector consists of an infinity of overlapping generations that go through two life-cycle states. Generations are born as workers. They remain active next period with probability $\omega_{t-1}$ and switch into retirement with probability $1-\omega_{t-1}$. Once retired, they survive with probability $\gamma_{t-1}$ and die with probability $1-\gamma_{t-1}$. With these probabilities

\footnotetext{
${ }^{8}$ Keuschnigg, Christian (2021), Consolidating the Covid Debt: A DSGE Model, Technical WP.
} 
being symmetric within each group, the total population with infinitely many vintages $N_{j, t}, j \leq t$, can be analytically aggregated into workers and retirees, $N_{t}=N_{t}^{W}+N_{t}^{R}$. The transition rates then determine the dynamics of the population structure by

$$
N_{t}^{W}=N_{t, t}^{W}+\omega_{t-1} N_{t-1}^{W}, \quad N_{t}^{R}=N_{t, t}^{R}+\gamma_{t-1} N_{t-1}^{R} .
$$

We keep population size constant by assuming that the inflow of newborns matches the outflow due to mortality among the old. However, to capture an increase in the effective retirement age, we specify an autoregressive process for the transition rate from work into retirement, $\omega_{t}=\left(1-\rho^{\omega}\right) \bar{\omega}+\rho^{\omega} \omega_{t-1}+\varepsilon_{t}^{\omega}$, where $\bar{\omega}$ is the long-run stationary rate, $\rho^{\omega}<1$ makes the change in the retirement propensity a slow process, and $\varepsilon_{t}^{\omega}$ is a stochastic disturbance used for estimation. We then compute an offsetting increase in the mortality rate $1-\gamma_{t}$ to keep population size constant in each period. Indeed, when retirement happens later, the old age group is composed with older people featuring higher mortality rates. We thus model an increase in the effective retirement age by increasing the survival rate among workers, making $N_{t}^{W}$ larger, while the mass of retirees $N_{t}^{R}$ declines on account of higher average mortality among older people. In other words, individuals spend less time in retirement. The economic dependency ratio $N_{t}^{R} / N_{t}^{W}$ thus falls and contributes to increased sustainability of the pension system.

Retirees: Assuming identical life-cycle characteristics within age groups allows for analytical aggregation of economic aggregates. The group of retirees basically behaves like a discrete version of the 'perpetual youth' model pioneered by Blanchard (1985). We follow Gertler (1999) and assume CES life-time utility $V_{j, t}^{R}=\left[\left(C_{j, t}^{R}\right)^{\mu}+\beta^{R} \gamma_{t}\left(V_{j, t+1}^{R}\right)^{\mu}\right]^{1 / \mu}$, where $\mu=1-1 / \sigma$ relates to the intertemporal elasticity of substitution $\sigma$. Expected future utility is discounted by $\beta^{R}<1$. Retirees obtain non-asset income $y_{t}^{R} \equiv\left(1-\tau_{t}\right) b_{t}+\tau_{t} t^{B}+b_{t}^{R}$ consisting of a per capita pension $b_{t}$, minus income tax $\tau_{t}\left(b_{t}-t^{B}\right)$ with $\tau_{t}$ being the marginal tax rate and $t^{B}$ a tax deduction, plus other untaxed social transfers. Retirees consume $C_{j, t}^{R}$ of the final good available at a consumer price $P_{t}^{c}$, and invest savings in a portfolio of assets with value $A_{j, t}^{R}$. The budget constraint is

$$
\gamma_{t} A_{j, t}^{R}=\left(1+\bar{\imath}_{t-1}\right) A_{j, t-1}^{R}+y_{t}^{R}-P_{t}^{c} C_{j, t}^{R},
$$


where $\bar{\imath}_{t-1}$ is the average return on the predetermined portfolio of assets, and $\gamma_{t}$ reflects the availability of reverse life-insurance contracts. Unplanned bequests are thereby redistributed among surviving retirees. Optimal consumption follows from expected utility maximization, with details given in the separate technical Appendix.

Workers: The value function of workers is $V_{j, t}^{W}=\left[\left(\bar{C}_{j, t}^{W}\right)^{\mu}+\beta^{W}\left(\bar{V}_{j, t+1}\right)^{\mu}\right]^{1 / \mu}$ in recursive form, depending on current utility $\bar{C}_{j, t}^{W}$ and expected utility next period equal to $\bar{V}_{j, t+1} \equiv \omega_{t} V_{j, t+1}^{W}+\left(1-\omega_{t}\right) V_{t+1, t+1}^{R}$. At any date, workers stay active with probability $\omega_{t}$, thereby expecting welfare $V_{j, t+1}^{W}$, or may become a new retiree with probability $1-\omega_{t}$, expecting welfare $V_{t+1, t+1}^{R}$. Current utility reflects consumption and effort. The participation rate $p^{r}$ in the young population is assumed exogenous. All participating family members individually search for a suitable job opportunity. Spending more effort, leading to progressively increasing effort cost $\varphi\left(n_{j, t}\right)$ per capita results in a higher probability $n_{j, t} \in[0,1]$ of finding a suitable job. With probability $1-n_{j, t}$, she is unlucky and remains 'unemployed'. We assume current utility to be separable in consumption and search effort, $\bar{C}_{j, t}^{W} \equiv C_{j, t}^{W}-p^{r} \varphi\left(n_{j, t}\right)$, where the effort cost is incurred only for participating members and is convex increasing in the employment rate.

Given identical life-cycle characteristics and separability of preferences makes the choice of the employment rate symmetric. Depending on search effort, each family member is employed with probability $n_{t}$ and earns a wage per capita of $w_{t}$, or is unemployed with probability $1-n_{t}$ and collects unemployment benefits $b_{t}^{l}=\bar{b}^{l} w_{t}$ which are indexed to wages and subject to tax. In addition, young families receive unconditional social benefits $b_{t}^{W}$ irrespective of the employment status of their members. The wage tax is linearly progressive. Given income pooling, active workers obtain expected earnings of $y_{t}^{W}=p^{r}\left[\left(1-\tau_{t}\right)\left(w_{t} n_{t}+\left(1-n_{t}\right) b_{t}^{l}\right)+\tau_{t} t^{B}\right]+b_{t}^{W}$. There is no mortality risk in the young life-cycle period. Wealth accumulation of a vintage $j$ family thus follows

$$
A_{j, t}^{W}=\left(1+\bar{\imath}_{t-1}\right) A_{j, t-1}^{W}+y_{j, t}^{W}-P_{t}^{c} C_{j, t}^{W}
$$

In assuming separable preferences over consumption and participation effort, we exclude intertemporal substitution in job search (see Heijdra, 1998). Optimal search effort 
thus depends on the current real income gain from accepting work over non-participation,

$$
\left(1-\tau_{t}\right)\left(w_{t}-b_{t}^{l}\right) / P_{t}^{c}=\varphi^{\prime}\left(n_{t}\right)
$$

Consumption and savings follow from life-time utility maximization, with details on optimization and aggregation given in the Technical Appendix. Spending on consumption is a fraction of life-time wealth, consisting of expected human wealth and accumulated financial wealth. Reflecting different expected life-time, the marginal propensity to consume of the old is higher than that of the young.

Aggregation: Saving smooths income differences across life-cycle periods. Analytical aggregation gives end of period asset wealth of retirees and workers,

$$
S_{t}^{R}=\left(1+\bar{\imath}_{t-1}\right) A_{t-1}^{R}+y_{t}^{R} N_{t}^{R}-P_{t}^{c} C_{t}^{R}, \quad S_{t}^{W}=\left(1+\bar{\imath}_{t-1}\right) A_{t-1}^{W}+y_{t}^{W} N_{t}^{W}-P_{t}^{c} C_{t}^{W} .
$$

At the end of $t$, a fraction $1-\omega_{t}$ of workers retires and a fraction $\omega_{t}$ remains active. After demographic change, assets of next period's workers and retirees are

$$
A_{t}^{W}=\omega_{t} S_{t}^{W}, \quad A_{t}^{R}=S_{t}^{R}+\left(1-\omega_{t}\right) S_{t}^{W}
$$

In particular, aggregate assets of retirees next period consist of savings $S_{t}^{R}$ of existing retirees plus assets $\left(1-\omega_{t}\right) S_{t}^{W}$ of new retirees who start retirement with assets previously saved in their active work-life. Assets of the deceased are distributed among surviving retirees. The premium from reverse life-insurance reflects redistribution and doesn't add wealth so that $\gamma_{t}$ cancels out in aggregation. Finally, asset wealth and consumption of the entire population are $A_{t}=A_{t}^{W}+A_{t}^{R}$ and $C_{t}=C_{t}^{R}+C_{t}^{W}$. Adding up (6) and using (5) finally gives aggregate asset accumulation

$$
A_{t}=\left(1+\bar{\imath}_{t-1}\right) A_{t-1}+Y_{t}^{N}-P_{t}^{c} C_{t}, \quad Y_{t}^{N}=y_{t}^{W} N_{t}^{W}+y_{t}^{R} N_{t}^{R} .
$$

\subsection{Production}

Value Added: Modeling VAT requires interindustry shipments with at least two sectors. All sectors use 'raw' value added $Y_{t}^{v}$ traded at a price $p_{t}^{v}$. Value added output is

$$
Y_{t}^{v}=u_{t} F\left(K_{t-1}, L_{t}, \bar{K}\right)=a_{t} u_{t} K_{t-1}^{\alpha} L_{t}^{1-\alpha-\bar{\alpha}} \bar{K}^{\bar{\alpha}}
$$


Introducing a fixed factor $\bar{K}$ create rents (entrepreneurship, land, monopolistic profits etc.). We follow Bayer et al (2020) in modelling a pandemic shock $u_{t}$. This shock affects output by preventing employees to work, either due to quarantine or to government intervention. Firms are forced to "mothball" a matching fraction of the capital stock, leaving it unused during the crisis. The pandemic thus leads to output losses due to under-utilization of factors, with $u_{t} \leq 1$ being the utilization rate.

Intermediate Goods: The final good is internationally traded at a price $P_{t}=1$. It is produced from two intermediate inputs $y_{t}^{1}$ and $y_{t}^{2}$, using a Leontief technology. Final demand $Y_{t}^{d}$ needs inputs $y_{t}^{1} \geq \phi Y_{t}^{d}$ and $y_{t}^{2} \geq(1-\phi) Y_{t}^{d}$ where $\phi$ is unit demand for good 1. Cost minimization gives $y_{t}^{i}=\phi^{i} Y_{t}^{d}$. Perfect competition determines prices $p_{t}^{i}$ by the zero profit condition $Y_{t}^{d}-\sum_{i} p_{t}^{i} y_{t}^{i}=0$. In equilibrium, input prices are related by

$$
\phi p_{t}^{1}+(1-\phi) p_{t}^{2}=1
$$

In a minimal model of interindustry relations, total supply of good $i$ must serve final demand $y_{t}^{i}$ plus intermediate demand $\tilde{y}_{t}^{j i}$ from the other industry $j$, giving gross output $\tilde{y}_{t}^{i}=y_{t}^{i}+\tilde{y}_{t}^{j i}$. Production uses value added $v_{t}^{i} \geq(1-\xi) \tilde{y}_{t}^{i}$ and a quantity $\tilde{y}_{t}^{i j} \geq \xi \tilde{y}_{t}^{i}$ of other goods. Parameter $\xi$ measures the depth of the supply chain. Using $\tilde{y}_{t}^{j i}=\xi \tilde{y}_{t}^{j} \operatorname{links}$ outputs by $\tilde{y}_{t}^{1}=y_{t}^{1}+\xi \tilde{y}_{t}^{2}$ and $\tilde{y}_{t}^{2}=y_{t}^{1}+\xi \tilde{y}_{t}^{1}$ where $y_{t}^{i}=\phi^{i} Y_{t}$ goes to final demand. The simultaneous solution is

$$
\tilde{y}_{t}^{1}=\frac{1}{1-\xi^{2}}\left(y_{t}^{1}+\xi y_{t}^{2}\right), \quad \tilde{y}_{t}^{2}=\frac{1}{1-\xi^{2}}\left(y_{t}^{2}+\xi y_{t}^{1}\right)
$$

Sectoral value added is $v_{t}^{i}=(1-\xi) \tilde{y}_{t}^{i}$ and $v_{t}^{1}+v_{t}^{2}=Y_{t}^{v}$ in total,

$$
Y_{t}^{v}=(1-\xi) \cdot\left(\tilde{y}_{t}^{1}+\tilde{y}_{t}^{2}\right)=y_{t}^{1}+y_{t}^{2}=Y_{t}^{d}
$$

where the last equality uses $y_{t}^{i}=\phi^{i} Y_{t}^{d}$.

Prices and VAT: The standard VAT rate is $\tau_{t}^{v}$. Suppose industry 1 is tax favored and subject to a reduced rate of $\tau_{t}^{1}$, which could possibly be zero, $\tau_{t}^{v}>\tau_{t}^{1} \geq 0$. Industry 1 may not be allowed to deduct the tax on intermediate inputs $\left(t^{1}=0\right.$, no deduction, 
$t^{1}=1$, full deduction). Sectoral profits and tax liabilities are

$$
\begin{array}{ll}
\pi_{t}^{1}=\left(1+\tau_{t}^{1}\right) p_{t}^{1} \tilde{y}_{t}^{1}-p_{t}^{v} v_{t}^{1}-\left(1+\tau_{t}^{v}\right) p_{t}^{2} \tilde{y}_{t}^{12}-T_{t}^{1}, & T_{t}^{1}=\tau_{t}^{1} p_{t}^{1} \tilde{y}_{t}^{1}-t^{1} \tau_{t}^{v} p_{t}^{2} \tilde{y}_{t}^{12}, \\
\pi_{t}^{2}=\left(1+\tau_{t}^{v}\right) p_{t}^{2} \tilde{y}_{t}^{2}-p_{t}^{v} v_{t}^{2}-\left(1+\tau_{t}^{1}\right) p_{t}^{1} \tilde{y}_{t}^{21}-T_{t}^{2}, & T_{t}^{2}=\tau_{t}^{v} p_{t}^{2} \tilde{y}_{t}^{2}-\tau_{t}^{1} p_{t}^{1} \tilde{y}_{t}^{21}
\end{array}
$$

Tax parameters $\tau_{t}^{1}$ and $t^{1}$ capture several regimes: (i) The standard VAT without tax privileges requires $\tau_{t}^{1}=\tau_{t}^{v}$ and $t^{1}=1$; (ii) Exemption is captured by $\tau_{t}^{1}=0=t^{1}$ and gives a zero tax liability, $T_{t}^{1}=0$. Industry 1 doesn't pay tax but also cannot deduct the input tax; (iii) Zero rating implies $\tau_{t}^{1}=0$ and $t^{1}=1$ and is more generous, giving tax refunds $T_{t}^{1}=-\tau_{t}^{v} p_{t}^{2} \tilde{y}_{t}^{12}$ to industry 1 ; (iv) Some industries are subject to reduced rates and are also granted deductions, $\tau_{t}^{1}<\tau_{t}^{v}$ and $t^{1}=1$.

Substituting for tax liabilities gives $\pi_{t}^{1}=p_{t}^{1} \tilde{y}_{t}^{1}-p_{t}^{v} v_{t}^{1}-\left(1+\left(1-t^{1}\right) \tau_{t}^{v}\right) p_{t}^{2} \tilde{y}_{t}^{12}$ as well as $\pi_{t}^{2}=p_{t}^{2} \tilde{y}_{t}^{2}-p_{t}^{v} v_{t}^{2}-p_{t}^{1} \tilde{y}_{t}^{21}$. Using input demands $v_{t}^{i}=(1-\xi) \tilde{y}_{t}^{i}$ and $\tilde{y}_{t}^{i j}=\xi \tilde{y}_{t}^{i}$ and imposing zero profits gives a price system $p_{t}^{1}=(1-\xi) p_{t}^{v}+\left(1+\left(1-t^{1}\right) \tau_{t}^{v}\right) \xi \cdot p_{t}^{2}$ together with $p_{t}^{2}=(1-\xi) p_{t}^{v}+\xi \cdot p_{t}^{1}$. The simultaneous solution is (use $\left.(1-\xi)(1+\xi)=1-\xi^{2}\right)$

$$
\begin{aligned}
& p_{t}^{1}=m_{t}^{1} \cdot p_{t}^{v}, \quad m_{t}^{1} \equiv \frac{1+\left(1-t^{1}\right) \tau_{t}^{v} \xi /(1+\xi)}{1-\left(1-t^{1}\right) \tau_{t}^{v} \xi^{2} /\left(1-\xi^{2}\right)} \geq 1, \\
& p_{t}^{2}=m_{t}^{2} \cdot p_{t}^{v}, \quad m_{t}^{2} \equiv \frac{1}{1-\left(1-t^{1}\right) \tau_{t}^{v} \xi^{2} /\left(1-\xi^{2}\right)} \geq 1 .
\end{aligned}
$$

If the tax on inputs is fully deductible $\left(t^{1}=1\right)$, prices would not be affected by VAT, $p_{t}^{i}=p_{t}^{v}$, which gives $p_{t}^{v}=1$ by (9). VAT distortions arise if the input tax is not deductible $\left(t^{1}=0\right)$. The tax thus inflates costs in sector 1 , leading firms to charge a higher producer price, $p_{t}^{1}>1$, which harms other industries. Sector 2 pays $\left(1+\tau_{t}^{1}\right) p_{t}^{1} \tilde{y}_{t}^{21}$ for inputs from sector 1 , claims back the tax $\tau_{t}^{1} p_{t}^{1} \tilde{y}_{t}^{21}$ and is left with a net cost of $p_{t}^{1} \tilde{y}_{t}^{21}$. However, sector 1 charges higher producer prices $p_{t}^{1}>p_{t}^{v}$ which inflates input costs in sector 2 as well. In consequence, sector 2 firms must also raise their prices, although to a smaller extent. The problem arises with exemptions $\left(t^{1}=0\right)$. Taxes remain in the supply chain and lead to cumulative cost increases and finally to higher prices $p_{t}^{1}$ and $p_{t}^{2}$.

When firms add VAT on their invoices, customers pay tax inclusive prices $\left(1+\tau_{t}^{1}\right) p_{t}^{1}$ and $\left(1+\tau_{t}^{v}\right) p_{t}^{2}$. By assumption, all agents have the same unit demands $\phi$ and $1-\phi$ for 
intermediate goods. The government buys final goods $G_{t}$ as inputs to producing public goods and services, and deducts VAT on inputs. The same applies to investment firms and exporters with demand $Z_{t}$ and $X_{t}$. Only consumers pay VAT. The budget constraint (with perfect competition and zero profit) relates final and intermediate goods prices by

$$
P_{t}=\phi p_{t}^{1}+(1-\phi) p_{t}^{2}=1, \quad P_{t}^{c}=\phi\left(1+\tau_{t}^{1}\right) p_{t}^{1}+(1-\phi)\left(1+\tau_{t}^{v}\right) p_{t}^{2}
$$

Consumers must pay VAT, giving a tax inclusive price $P_{t}^{c}$, while other buyers are eligible to VAT refunds and pay a lower price, $P_{t}^{c}>P_{t}=1$. However, VAT exemptions inflate prices

$p_{t}^{i}$. Since the final goods price is fixed on world markets $\left(P_{t}=1\right)$, higher intermediate goods prices imply a lower value added price $p_{t}^{v}$ in equilibrium. Depending on the extent of the problem, the VAT not only reduces labor supply, but also investment and exports, thereby harming growth and international competitiveness. An ideal $\operatorname{VAT}\left(\tau_{t}^{1}=\tau_{t}^{v}\right.$ and $\left.t^{1}=1\right)$ doesn't affect input prices, $p_{t}^{i}=p_{t}^{v}$, and gives a consumer price of $P_{t}^{c}=\left(1+\tau_{t}^{v}\right) P_{t}$. The final goods price is given on international markets. With $P_{t}=1$ fixed, the value added price $p_{t}^{v}$ must adjust. Substituting $p_{t}^{i}=m_{t}^{i} \cdot p_{t}^{v}$ from (13) into the price index (14) gives

$$
P_{t}=1 \quad \Rightarrow \quad p_{t}^{v}=1 /\left(\phi m_{t}^{1}+(1-\phi) m_{t}^{2}\right)
$$

When VAT inflates intermediate goods prices, the value added price must fall in equilibrium to compensate these price increases. Much like a productivity slowdown, VAT distortions thus impair growth by reducing the value added price and international competitiveness by deteriorating the terms of trade.

\subsection{Investment}

Personal Capital Income Taxes: Austria has a dual income tax where interest on corporate, government and foreign bonds and dividends are all subject to a uniform 'savings' tax at rate $\tau^{s}$. By the residence principle, domestic investors must tax interest earnings on worldwide personal capital income which equates the domestic gross interest to the world market rate, $i_{t}=i^{*}$. The domestic net of tax interest rate is thus $\left(1-\tau_{t}^{s}\right) i^{*}$ and thereby endogenous to savings taxation. 
Capital gains are taxed at the same statutory rate. However, the tax applies only to realized capital gains so that capital gains remain untaxed until realization. Deferred taxation reduces the effective tax rate to $\tau_{t}^{g}<\tau_{t}^{s}$. With dividends and capital gains taxed differently, the effective tax on equity returns is $\tau_{t}^{e}=\theta \tau_{t}^{s}+(1-\theta) \tau_{t}^{g}$, a weighted average of the two rates. Much in line with empirical evidence, we assume sticky dividends such that firms receive a constant base dividend plus a marginal dividend, the size of which is determined by the parameter $\theta$. The detailed arguments are in the separate Technical Appendix. The firm's discount rate then follows from a no-arbitrage condition, $\left(1-\tau_{t}^{e}\right) r_{t-1}=i_{t-1}^{e}=\left(1-\tau_{t}^{s}\right) i_{t-1}+\bar{r}^{e}$. Equity investors thus require a net of tax return $i_{t-1}^{e}$ equal to the net return on other assets plus an equity premium $\bar{r}^{e}$. To guarantee this return net of dividend and capital gains taxes, i.e., net of the effective tax $\tau_{t}^{e}$, firms must earn a pre-tax return $r_{t-1}$ satisfying $\left(1-\tau_{t}^{e}\right) r_{t-1}=i_{t-1}^{e}$. Since dividend stickiness makes $\tau_{t}^{e}$ a weighted average of dividend and capital gains tax rates, our formulation thus implements the 'old view' of dividend taxation. Both dividend and capital gains taxation affect the firm's discount rate and, in turn, investment decisions. In addition, dividends and retained earnings are well determined and not residual.

Financial Identities: Firms optimally invest and choose capital structure to maximize firm value, taking the gross return on equity $r_{t}$ required by investors as given. Capital accumulation follows $K_{t}=I_{t}+(1-\delta) K_{t-1}$, where $\delta$ is the depreciation rate and $I_{t}$ gross investment. Assets $K_{t}$ are financed with debt and equity which accumulate by

$$
B_{t}=N_{t}^{B}+(1-\delta) B_{t-1}, \quad E_{t}=N_{t}^{E}+V_{t}^{N}+(1-\delta) E_{t-1} .
$$

We assume that debt is repaid whenever the underlying capital good depreciates. Depreciation thus reduces assets and liabilities (equity and debt) by the same proportion so that the balance sheet shrinks by $\delta K_{t-1}$. The balance sheet at the end of $t$ is $K_{t}=E_{t}+B_{t}$, which relates financial flows by $I_{t}=N_{t}^{B}+N_{t}^{E}+V_{t}^{N}$. Investment is financed with new debt $N_{t}^{B}$ and new equity, consisting of retained earnings $N_{t}^{E}$ and new share issues $V_{t}^{N}$.

Revenues of the business sector stem from final demand which is linked to value added production by an input output coefficient of one, $Y_{t}^{v}=Y_{t}^{d}$. Subtracting the costs of 
intermediate inputs yields net revenues $p_{t}^{v} Y_{t}^{v}$. To account for persistence in employment and investment, we introduce adjustment costs internal to the firm, reflecting additional costs of reorganization whenever investment and employment deviate from trend growth, $J_{t}^{L}$ and $J_{t}^{I} \cdot{ }^{9}$ In the aggregate, net revenues are equal to GDP,

$$
Y_{t}=p_{t}^{v} Y_{t}^{v}-J^{I}\left(I_{t}, I_{t-1}\right)-J^{L}\left(L_{t}, L_{t-1}\right), \quad Y_{t}^{v}=u_{t} F\left(K_{t-1}, L_{t}, \bar{K}\right)
$$

The utilization rate is $u_{t}=1$ in normal times and $u_{t}<1$ in a pandemic. In a pandemic, firms receive a temporary wage subsidy $s_{t}$ per unit of labor which is designed to insure wage earnings and keep up employment. To compensate for temporary losses and avoid widespread business failure, firms receive lump-sum subsidies $s_{t}^{k}$ (e.g., fixed cost subsidies). Cash-flow $\pi_{t}$ and profit tax liability $T_{t}^{k}$ are

$$
\begin{aligned}
\pi_{t} & =Y_{t}+s_{t} L_{t}+s_{t}^{k}-w_{t} L_{t}-i_{t-1} B_{t-1}, \\
T_{t}^{k} & =\tau_{t}^{k}\left(\pi_{t}-\tilde{\imath}_{t-1}^{E} \tilde{E}_{t-1}-t^{I} I_{t}-\delta K_{t-1}\right), \\
\tilde{E}_{t} & =t^{E}\left(N_{t}^{E}+V_{t}^{N}\right)+(1-\delta) \tilde{E}_{t-1} .
\end{aligned}
$$

The Covid shock is reflected in a sudden decline in the utilization rate $u_{t}<1$. Temporary subsidies $s_{t} L_{t}+s_{t}^{k}$ partly replace the loss of cash-flow $\pi_{t}$. The corporate tax rate is $\tau_{t}^{k}$. The tax base is cash-flow minus depreciation $\delta K_{t-1}$, deduction of a share $t^{I}$ of investment spending (accelerated depreciation, immediate write-offs). Firms may also deduct notional interest $\tilde{\imath}_{t-1}^{E}$ on eligible equity $\tilde{E}_{t-1}$. Currently, $t^{E}=\tilde{E}=0$. When changing to an ACE system ( $\operatorname{set} t^{E}=1$ ), we assume that only new equity $N_{t}^{E}+V_{t}^{N}$ qualifies for interest deductions. Eligible equity starts at $\tilde{E}=0$ under the current system, accumulates with $N_{t}^{E}+V_{t}^{N}$ and eventually approaches $\tilde{E} \rightarrow E$. Limiting deductions to new equity leads to a slow reduction of the tax base and avoids windfall gains or losses.

Firms choose employment, investment and new debt to maximize value. We state the main results and refer to the Technical Appendix for technical details of optimization. We assume that debt capacity is limited to a fraction $b^{k}$ of total assets, $B_{t} \leq b^{k} K_{t}$. Since

\footnotetext{
${ }^{9} \mathrm{In}$ line with standard DSGE approach, we assume quadratic adjustment costs $J^{L}\left(L_{t}, L_{t-1}\right)=$ $\psi^{L}\left(L_{t} / L_{t-1}-1\right)^{2} L_{t} / 2$ and $J^{I}\left(I_{t}, I_{t-1}\right)=\psi^{I}\left(I_{t} / I_{t-1}-1\right)^{2} I_{t} / 2$.
} 
equity is more expensive than debt $\left(i_{t}^{e}>i_{t}\right)$, firms prefer debt financing so that the capital constraint binds. The parameter $b^{k}$ thus determines capital structure. Employment follows from $p_{t}^{v} u_{t} F_{L, t}+s_{t}=w_{t}+\tilde{w}_{t}$ where $\tilde{w}_{t}$ are marginal adjustment costs. Deviations from stationary levels creates adjustment costs which dampen short-run fluctuations. The wage subsidy is meant to keep up employment and compensate for wage losses of workers. Setting the pandemic subsidy rate at $s_{t}=\left(1-u_{t}\right) p_{t}^{v} F_{L, t}$ thus gives $p_{t}^{v} F_{L, t}=w_{t}+\tilde{w}_{t}$. The large fiscal costs are debt financed. In normal, non-pandemic times, $u_{t}=1$ and $s_{t}=0$, and $\tilde{w}_{t}=0$ in a steady state. Employment satisfies $p^{v} F_{L}=w$.

Finally, investment is subject to adjustment costs and follows Tobin's $Q$-theory. The marginal value of capital reflects the present value of future earnings. Whenever this present value exceeds acquisition costs, investment picks up, but to a smaller extent if marginal adjustment costs are high. In a steady state, adjustment costs are absent, and investment just replaces depreciated capital, $I_{t}=\delta K_{t}$. The user cost of capital is

$$
p^{v} F_{K}=\frac{r-t^{E} \tau^{k} \tilde{\imath}^{E}}{1-\tau^{k}} \cdot\left(1-b^{k}\right)+i \cdot b^{k}+\delta-(r+\delta) \frac{t^{I} \tau^{k}}{1-\tau^{k}} .
$$

This formula nests several cases: (i) The standard formula $p^{v} F_{K}=\bar{r}+\delta$ emerges in the absence of tax where $\bar{r} \equiv r \cdot\left(1-b^{k}\right)+i \cdot b^{k}$ is the weighted funding cost; (ii) In the present system, the cost of equity is not deductible, $t^{E}=0$. The tax substantially inflates the cost of equity $\frac{r}{1-\tau^{k}}$. The cost of debt, in contrast, is not affected since interest on debt is tax deductible. However, there are also some tax incentives for investment $t^{I}>0$ such as accelerated depreciation or immediate expensing. They reduce the cost of capital irrespective of funding structure and make the tax somewhat less damaging to investment; (iii) An ACE tax allows a deduction of a notional return on equity, $t^{E}=1$ with $\tilde{\imath}^{E}=r$, equal to the opportunity cost of equity. In this case, the tax no longer affects the cost of equity which reduces to $r$ instead of $r /\left(1-\tau^{k}\right)$. To avoid subsidizing capital, all tax incentives to investment must be cancelled, $t^{I}=0$. The user cost reduces to $p^{v} F_{K}=r \cdot\left(1-b^{k}\right)+i \cdot b^{k}+\delta=\bar{r}+\delta$ as without tax. The government continues to tax rents while a normal return is tax exempt. Tax revenue significantly declines. 


\subsection{Fiscal Sector}

On top of pensions $b_{t}$ and social spending $b_{t}^{l}$ for non-participating workers, the government grants per capita lump-sum transfers to workers and retirees, $b_{t}^{W}$ and $b_{t}^{R}$. Social spending is $G_{t}^{B}=\left(b_{t}+b_{t}^{R}\right) N_{t}^{R}+\left(b_{t}^{l}\left(1-n_{t}\right) p^{r}+b_{t}^{W}\right) N_{t}^{W}$. The government must also provide public services $G_{t}$. Tax revenue is $T_{t}=\tau_{t}\left(w_{t} n_{t}-t^{B}\right) p^{r} N_{t}^{W}+\tau_{t}\left(b_{t}-t^{B}\right) N_{t}^{R}+T_{t}^{v}+T_{t}^{k}+T_{t}^{s}$ and stems from wage tax revenue on workers and pensioners, plus taxes $T_{t}^{k}$ and $T_{t}^{s}$ on profits and personal capital income (interest, dividends, capital gains), plus VAT $T_{t}^{v}$. In the pandemic, the government additionally spends on wage subsidies $s_{t} L_{t}$ and subsidies $s_{t}^{k}$ to partly compensate vanishing profits. The fiscal budget constraint is

$$
D_{t}=\left(1+i_{t-1}\right) D_{t-1}-S_{t}-\tilde{S}_{t}
$$

The government emits bonds $D_{t}$ at a risk-free interest $i_{t}$. A key aspect of our analysis is the distinction between a structural (target) component $S_{t}$ of the fiscal surplus and a temporary component $\tilde{S}_{t}$ which is especially critical in times of crisis. For this purpose, we define 'structural' tax revenue $\bar{T}_{t}$ which is smoothed over time, and actual tax revenue $T_{t}$ as discussed above. The primary surplus thus splits up into the components

$$
S_{t}=\bar{T}_{t}-G_{t}-G_{t}^{B}, \quad \tilde{S}_{t}=-\left(\bar{T}_{t}-T_{t}-s_{t} L_{t}-s_{t}^{k}\right)
$$

In recessions, actual tax revenue falls below trend and creates temporary deficits, together with pandemic subsidies $s_{t} L_{t}$ and $s_{t}^{k}$. In normal times, $\tilde{S}_{t}=0$ so that debt accumulation depends on the structural surplus $S_{t}$. To consolidate debt, the government must cut expenditure entitlements or scale up tax rates to increase structural tax revenue.

Preventing explosive debt requires a consolidation rule. Maastricht type rules are concerned with structural imbalances. We assume that the government targets a time path for debt to GDP ratios, where the debt ratio $d_{t}$ is defined relative to a slow moving 'potential output' $Y_{t}^{a}=\rho^{y} Y_{t-1}^{a}+\left(1-\rho^{y}\right) Y_{t}$,

$$
d_{t}=\nu d_{t-1}+(1-\nu) \bar{d}-\tilde{S}_{t} / Y_{t}^{a}+\varepsilon_{t}^{D}, \quad d_{t}=D_{t} / Y_{t}^{a}
$$


We allow for a stochastic fiscal rule with policy errors $\varepsilon_{t}^{D}$. Temporary deficits $\tilde{S}_{t}<0$ are not consolidated and are allowed to increase the debt ratio. The consolidation policy thus determines a new debt level $D_{t}=d_{t} Y_{t}^{a}$, and implicitly pins down the tax scaler. Importantly, the speed of fiscal consolidation is governed by the parameter $\nu$.

\subsection{Equilibrium}

Households invest savings $A_{t}$ in equity $V_{t+1}$, government bonds $D_{t}$, business debt $B_{t}$ and other assets $D_{t}^{f}$ (foreign bonds). Total financial wealth is

$$
A_{t}=D_{t}^{f}+D_{t}+B_{t}+V_{t+1}
$$

Bonds (business, government and foreign) are perfect substitutes and yield the same net return $\left(1-\tau_{t+1}^{s}\right) i_{t}$ while equity wealth yields a higher return $i_{t}^{e}$. The average, expected portfolio return of household investors is $\bar{\imath}_{t}=s_{t}^{v} \cdot i_{t}^{e}+\left(1-s_{t}^{v}\right) \cdot\left(1-\tau_{t+1}^{s}\right) i_{t}$, depending on the portfolio share $s_{t}^{v}=V_{t+1} / A_{t}$. Portfolio structure is determined by the supply of assets. All households hold identical portfolios, independent of their level of wealth.

Net exports $X_{t}$ (trade surplus) create net foreign wealth. The current account is

$$
D_{t}^{f}=\left(1+i_{t-1}\right) D_{t-1}^{f}+X_{t}, \quad X_{t}=Y_{t}-C_{t}-G_{t}-I_{t} .
$$

The price normalization $P_{t}=1$ implies that $X_{t}$ is the quantity of net exports equal to the value of the trade balance surplus which reflects excess savings, i.e., income minus absorption. The surplus is invested in foreign bonds (NFA) $D_{t}^{f}$. In a small open economy, free arbitrage equates domestic and foreign interest, $i=i^{*}$, with $i^{*}$ exogenous.

Capital markets clear by the portfolio budget. Labor and goods markets clear if

$$
n_{t} N_{t}^{W}=L_{t}, \quad Y_{t}^{v}-J_{t}^{L}-J_{t}^{I}=C_{t}+G_{t}+I_{t}+X_{t}
$$

The quantity of final demand is $Y_{t}^{d}=Y_{t}^{v}$ as in (11). After subtracting internal absorption due to adjustment costs gives net market supply $Y_{t}^{v}-J_{t}^{L}-J_{t}^{I}$ of the final good. 


\section{Quantitative Analysis}

\subsection{The Covid Debt}

In the past twenty years, the debt to GDP ratio in Austria fluctuated in the range of 65 to 90 percent which is above the EU's Maastricht target ratio of $60 \%$. Figure 2 illustrates that the debt ratios in Austria and other EU and Euro Area member states were on a convergent path prior to the financial crisis in 2008 and the current Covid crisis.

In 2008 and 2019, Austria's debt ratio was roughly 69 and 71\% of GDP. An upward shift in public debt in the wake of catastrophic events such as the financial crisis 2008 and the current Covid 19 pandemic is consistent with the Maastricht rules, as they distinguish between structural and temporary imbalances. To smooth the economic cycle, the debt and deficit rules allow temporary spending increases or tax shortfalls to go into debt. In Austria, the debt increase in the wake of the current Covid pandemic is roughly comparable in magnitude to the developments after the financial crisis.

Once the Covid crisis is over, governments need to consolidate budgets and slowly reduce the debt ratios again. With the exception of Germany, the increase in public debt is even larger in other developed countries in- and outside the EU, as Figure 1 documents. Our analysis of growth friendly consolidation strategies should thus be informative for other countries as well.

To consolidate the Covid debt, countries must generate a larger fiscal surplus by adjusting tax and spending levers, preferably in a growth friendly way. In Austria, total fiscal spending (including pensions and social insurance) and tax revenue in 2019 were 48.6 and $49.2 \%$ of GDP, respectively. ${ }^{10}$ The largest part of revenue derives from taxes $(27.7 \%$ of GDP), with wage income tax (8.9\%) and VAT (7.7\%) contributing the lion's share. The corporate profit tax contributes $2.5 \%$ of GDP. The other pillar of fiscal revenue rests on social security contributions (15.4\% of GDP) which are roughly split evenly between

\footnotetext{
${ }^{10}$ Data are from Statistik Austria (2021b), unless otherwise specified
} 


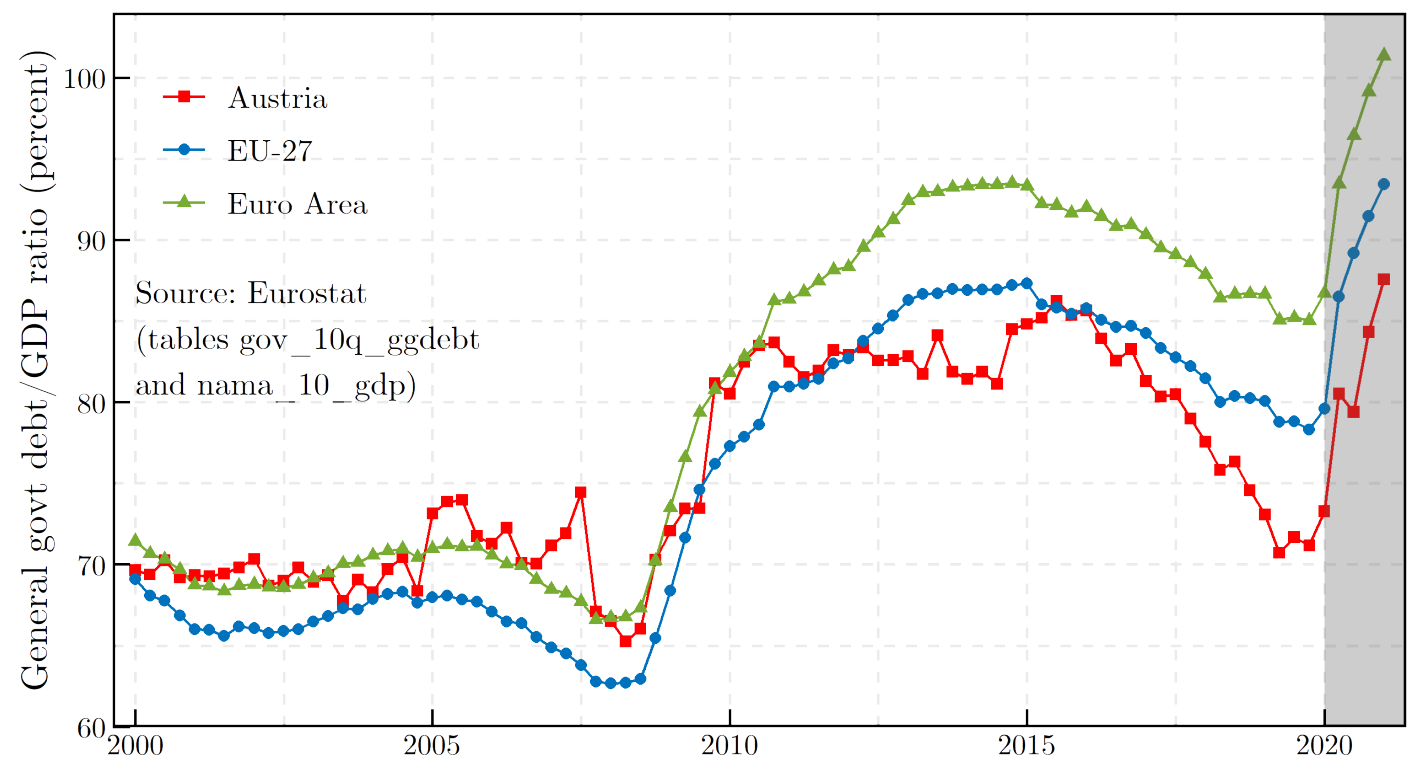

Figure 2: Government debt to GDP ratio

employers and employees. The remaining revenue (6.1\%) mainly derives from taxes and fees on production and property.

On the expenditure side, social protection is by far the largest item (20.1\% of GDP). Large allocations go to economic affairs (8.3\%), health (7.8\%), general public services $(5.2 \%)$ and education (4.3\%). The remainder of $3.9 \%$ of GDP is mainly spent on security and culture. The largest chunk of social protection is reserved for public pensions $(12.6 \%$ of GDP). Austria's public pension system is very generous, with a median gross replacement rate for men of $89.9 \%$ (OECD, 2021a). ${ }^{11}$ Contribution rates are high. Workers and employees contribute $10.25 \%$ of gross salaries and firms pay $12.55 \%$ of gross labour earnings. Austria's pension system is strained by an unusually low effective retirement age. In 2018, the mean age of retirement was 63.5 years for men and 60.8 for women (OECD, 2021a). Consequently, the system requires a large annual subsidy from the general fiscal budget. In 2019, this subsidy amounted to $2.4 \%$ of GDP and is projected to rise above $3 \%$ following 2021. In addition, the general government directly pays pensions to part

\footnotetext{
${ }^{11}$ Comparing the mean pension payment of $€ 21,238$ (Statistik Austria, 2021c) to mean household earnings of $€ 36,792$ (Eurostat, 2021) would result in an average replacement rate of about $58 \%$.
} 
of the civil servants, with a net fiscal cost of $2.9 \%$ of GDP after subtracting contributions (see the medium term report of the Austrian commission for old-age protection, (Alterssicherungskommission, 2021)).

\subsection{Fiscal Consolidation}

In the post-Covid era, governments confront the problem of consolidating the accumulated debt in a way that doesn't impair the economy's growth potential. At the same time, policy should achieve a reasonably fair inter-generational burden sharing. In reality, a large range of policy options is available. The present paper aims to contrast two polar strategies, a passive approach and a reform oriented consolidation strategy. Can a country 'grow out of the Covid debt' with pro-growth fiscal reform? Specifically, and taking the case of Austria as an example, is it possible to consolidate the Covid debt by reaping unexploited efficiency gains from fiscal reform without raising marginal tax rates and impairing individual entitlements?

\subsubsection{A Passive Approach}

We estimate the key parameters of the DSGE model to track past economic performance in terms of fluctuations around a stationary equilibrium prior to the Covid crisis (see Appendix). In a first step, we use the model to 'replicate' the crisis and the sudden increase in public debt. Following the literature discussed in Section 2, we mimic the Covid crisis as a temporary reduction in the utilization rate of labor and capital, leading to a large output loss over 10 quarters. The left hand side panel of Figure 3 illustrates.

To stabilize employment and protect workers, the government compensates the loss in wage income with temporary wage subsidies. Additional fixed cost subsidies and other emergency measures are motivated by the need to keep firms afloat and to prevent excessive business failure due to liquidity problems. We also assume that the government doesn't suddenly raise tax rates to compensate for revenue losses in the crisis but accepts 

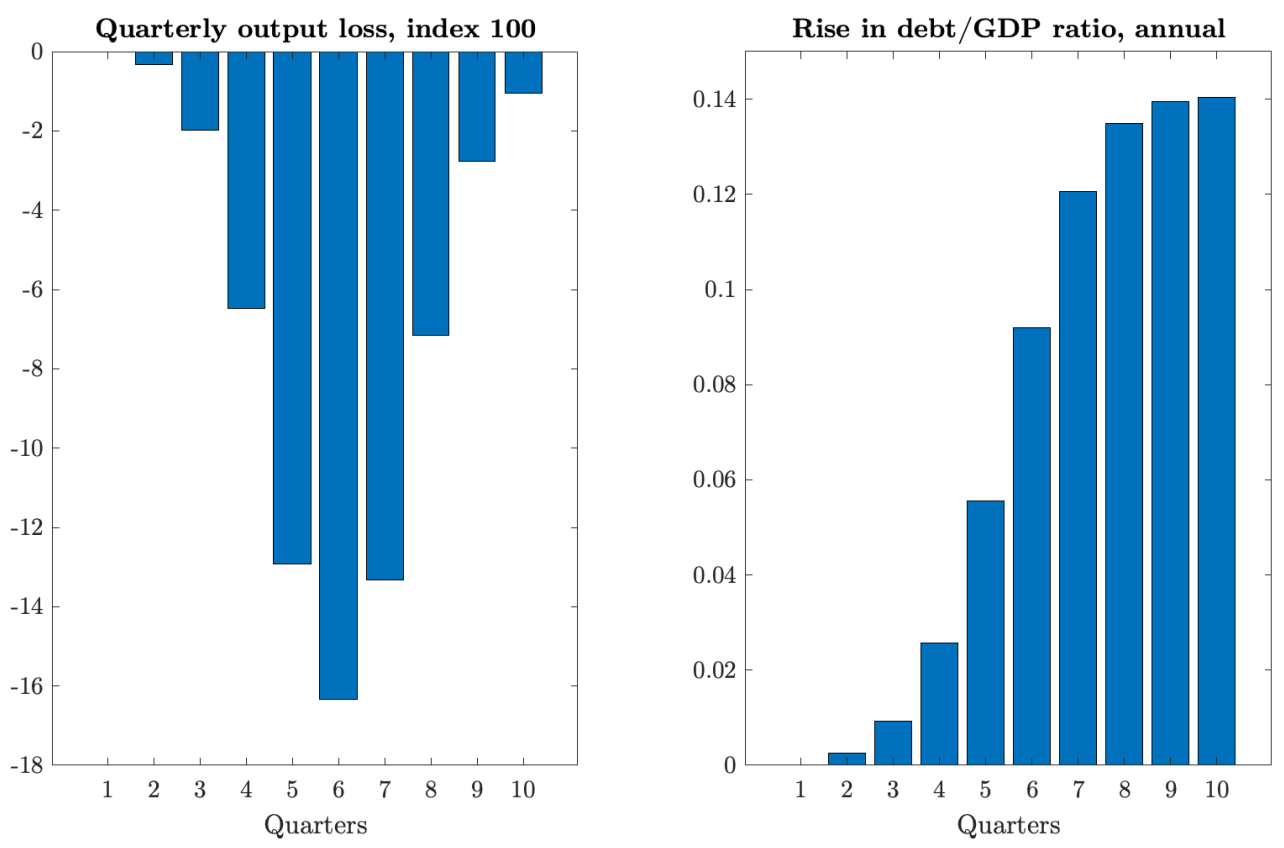

Figure 3: The Covid crisis

that a temporary loss of tax revenue goes into debt, see (21). ${ }^{12}$ The fiscal cost of the crisis thus triggers large temporary deficits which lead to a drastic increase in the debt to GDP ratio as shown in the r.h.s panel. Note that Figure 3 shows debt in percent of potential $G D P$ which is close to stationary GDP prior to the crisis. Otherwise, the increase in the debt to GDP ratio would be driven primarily by the temporary output loss in the denominator, rather than the higher level of debt.

We start by analyzing a passive consolidation strategy that (approximately) adheres to Maastricht rules. To generate the required primary surpluses, we uniformly scale all tax rates. To isolate the effects of consolidation, we compare to a 'no-consolidation' scenario where the government merely stabilizes the debt to GDP ratio at the level that was accumulated until the end of the Covid crisis (after 10 quarters, as in Figure 3). In

\footnotetext{
${ }^{12}$ We capture such inertia by making tax rates partly dependent on the rates levied in the previous period, making actual tax revenue deviate from what would be required to close the budget. Specifically, we scale all tax rates by a factor $t_{t}^{s}=\rho^{t} t_{t-1}^{s}+\left(1-\rho^{t}\right) t_{t}^{n}$ where $t_{t}^{n}$ would be the rate that avoids temporary revenue deviations. We estimate the degree of tax rate inertia to be $\rho^{t}=0.23$.
} 
Figure 4, the blue lines refer to this no-consolidation case. The red straight lines indicate the values at the end of the Covid shock. Thereafter, the economy converges to the equilibrium with a permanently higher debt ratio. The green lines depict the outcomes of a passive consolidation policy which restores the debt ratio prior to the crisis.

For better visibility, we do not include the Covid period but only show the development after 10 quarters. ${ }^{13}$ To study the consequences of an unexpected regime change, we take the values of the no-consolidation equilibrium in quarter 10 as initial conditions for the post Covid era. Stock variables such as capital or fiscal debt are predetermined and cannot jump. Forward looking variables such as investment and consumption jump to a new time path reflecting different expectations about the future after a policy change. In the noconsolidation scenario, illustrated by the blue lines, all time series develop continuously between the pre- and post-Covid era since there is no policy change. Expectations change and the economy moves along new trajectories (green lines) when the government switches policy and starts to consolidate the Covid debt.

In the no-consolidation scenario, the government merely prevents any further increases in the debt ratio. The debt to GDP ratio thus remains roughly at the higher level inherited from the Covid crisis. Compared to the pre-Covid steady state, the government must generate higher primary surpluses to stabilize debt and accordingly must permanently scale up all tax rates by a factor of 1.014. The necessary tax increases are rather negligible, for two reasons. First, interest rates are at a historical low, assumed to be equal to $2 \%$ per annum (0.5\% quarterly) in the steady state, and currently even lower. Second, the increase in the debt to GDP ratio is only 14 percentage points. The additional budget cost of the extra interest burden would be a mere $0.28 \%$ of GDP $(=.02 \times .14 \times 100)$. Of course, the budget burden could increase substantially if interest rates were to rise. With all tax rates and tax distortions higher, employment and investment are discouraged and GDP remains permanently lower.

\footnotetext{
${ }^{13}$ The huge Covid shock dwarfs all other changes. Including this period would not allow to visibly distinguish alternative paths in the post Covid era.
} 

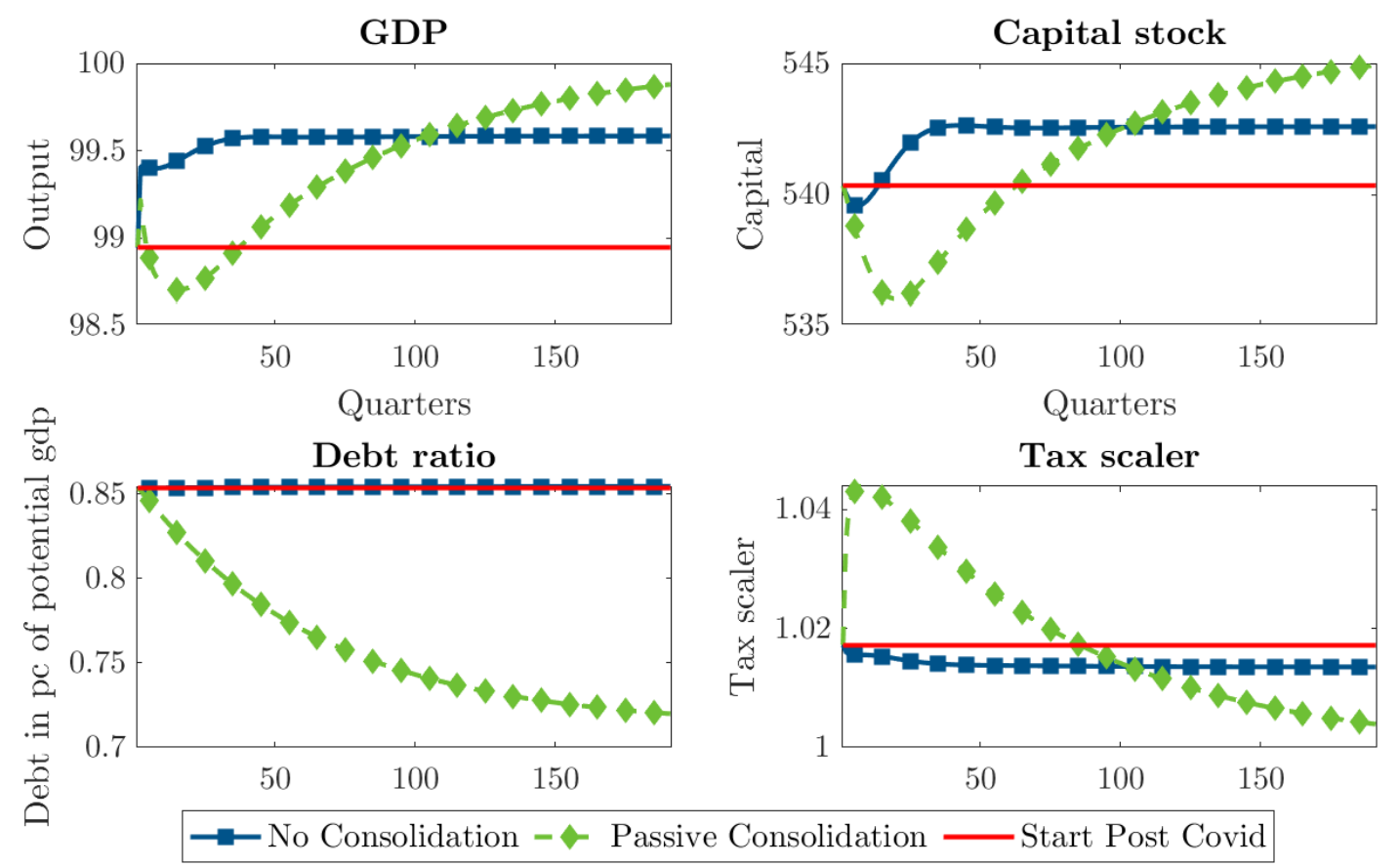

Figure 4: Stabilizing debt vs. consolidation

When consolidating the Covid debt, the government must generate higher primary surpluses in a first phase until the debt ratio approaches the pre Covid level. To avoid disruptive tax changes, consolidation is stretched over a longer time horizon, roughly consistent with Maastricht rules. The Figures reflect the estimated fiscal adjustment speed equal to .985 which implies very slow convergence to the target ratio of debt to GDP. The half-life of debt reduction is 45 quarters, somewhat faster than the 55 quarters implied by the Maastricht requirement for consolidation of at least $5 \%$ a year. Given this slow speed of consolidation, it takes more than 50 years (200 quarters) to come down again to the lower initial debt to GDP ratio of $71 \%$. We illustrate below the consequences of a more ambitious and faster consolidation of the Covid debt.

Figure 4 clearly illustrates the inter-temporal trade-off associated with fiscal consolidation. The government must scale up tax rates much more in the first phase to generate the required fiscal surpluses needed to partly repay debt. Since higher tax rates discourage employment and slow down capital accumulation, consolidation must necessarily accept 
an immediate decline in GDP. Once the reduction in the debt burden is large enough, the government starts to consume the benefits of consolidation by reducing tax rates below the levels in the no-consolidation scenario. When the debt to GDP ratio is down to the pre-Covid level, and without any other shocks occurring, the economy ultimately converges back to the initial growth path that would have obtained without the Covid shock (green lines in Figure 4). These results implicitly reflect the assumption that there are no long-lasting productivity reducing scarring effects of the Covid crisis.

\subsubsection{A Fiscal Consolidation Strategy}

We now combine fiscal consolidation with structural reform to reap potential efficiency gains. Is it possible to avoid the stark intergenerational trade-off and consolidate the Covid debt without raising marginal tax rates and impair welfare benefits of current and near future generations? The proposed consolidation strategy consists of several pillars that are introduced step by step to show the cumulative effects. Adding the last pillar yields the total results of the complete strategy.

Value Added Tax Reform (VAT): The first element of the consolidation strategy to facilitate convergence to lower debt is VAT reform. Our model of VAT distortions is admittedly rather stylised, but manages to capture the crucial elements of the distortion while remaining tractable. Using Leontief preferences and technology with fixed demand shares and input output coefficients allows for closed form solutions of sectoral production structure. Specifically, we assume that $18.9 \%$ of final demand $(\phi=0.189)$ is sourced from a tax favored sector $1 .{ }^{14}$ The bulk of demand is thus for output of sector 2. Sectoral output requires own value added (67.9\% of output value) and intermediate inputs from the other sector (32.1\%). We thus set $\xi=0.321$ to measure the depth of the supply chain with sector linkages (see sections 1.2.2 and 3). Sector 2 is subject to the normal VAT rate of $\tau^{v}=0.2$, equal to the $20 \%$ standard rate in Austria. Sector 1 goods qualify for a reduced rate of $\tau^{1}=0.1$. To reduce complexity, we collect in sector 1 all firms subject

\footnotetext{
${ }^{14}$ See the 2017 Austrian Input-Output tables (Statistik Austria, 2021a). Details are in the Appendix.
} 
to reduced or zero rates. Part of them is tax favored but is allowed to claim back VAT on intermediate inputs (tax parameter $t^{1}=1$ ). Others are exempt but are not entitled to refunding of the input $\operatorname{tax}\left(t^{1}=0\right)$. If firms cannot get back the input tax, then VAT partly remains in the supply chain and ultimately taxes not only private consumption but all final demand including investment, exports and public consumption.

Our first proposal recommends to move to an 'ideal VAT' with a uniform rate $\left(\tau^{1}=\tau^{v}\right)$ and complete refunding of input taxes $\left(t^{1}=1\right)$ in both sectors. While raising the reduced rate to the normal level strengthens the tax yield, moving to full refunding of input taxes is costly and may, on net, lead to lower VAT revenue. The major benefits are the efficiency gains from restoring the consumption tax character. Although even a pure VAT reduces real wages and discourages labor supply, the elimination of VAT exemptions stimulates growth by removing input distortions. The reform works like a productivity increase that raises the effective value added price $p^{v}$ and thereby stimulates investment, employment and output. Any revenue gains or losses due to the reform are used to scale down or up all marginal tax rates across the board. Our model is not detailed enough to capture the distributional consequences. However, distributional objectives are better pursued by using the targeted tax transfer mechanism with a progressive income tax.

Corporate Tax Reform (ACE): According to current tax practice, interest on debt is tax deductible while the cost of equity is not. Depending on the share of equity in total financing, the tax thus raises the cost of capital to firms and discourages investment. ${ }^{15}$ To establish full investment neutrality, an ACE reform introduces a tax deduction for a notional return on equity $\tilde{l}^{E}$ equal to the firm's discount rate which includes an equity premium on top of safe interest. ${ }^{16}$ In exchange, investment neutrality requires that existing investment tax credits are abolished. This will reduce the induced growth effects

\footnotetext{
${ }^{15}$ It also leads to a tax bias for using debt rather than equity and thereby undermines the crisis resilience of firms. Our analysis focuses on growth effects of tax reform. We thus treat capital structure as fixed, i.e. $34 \%$ of assets are backed up with equity and $66 \%$ with debt.

${ }^{16}$ Bond and Devereux (1995) argue that the notional interest could be either safe interest coupled with complete loss offset, or a higher risky return including an equity premium if loss-offset is denied.
} 
to some extent. To limit the budget cost and avoid windfall gains, the proposal allows notional interest deductions only on new equity while the returns on existing equity are fully taxed as before. To this end, we introduce a stock of eligible equity that is built up slowly with new investment spending net of debt financing. Over time, eligible equity continuously increases until, eventually, the notional interest on the entire equity stock is tax deductible. This reform design immediately strengthens investment incentives and boosts growth while the losses in tax revenue materialize only slowly. In the long-run, the loss in corporate tax revenue is substantial since the normal, competitive return on capital is fully tax deductible. However, excess returns due to economic rents continue to be subject to tax and still generate significant revenue.

Postponed Retirement (RET): The effective retirement age in Austria is one of the lowest in the EU. Own contributions roughly pay for only three quarters of pensions. The remaining quarter is covered by large transfers from the general budget. The need for budget consolidation makes it more urgent to balance the pension system. Instead of raising contribution rates which are already very high, or cutting benefits which are meant to protect living standards and avoid old age poverty, an increase in the retirement age is arguably the best way to balance the system.

Evidence suggests that raising the average, effective retirement age by one year boosts total labor supply by about $2.3 \% .17$ Our scenario is reasonably conservative in assuming that the government can implement an increase in the effective retirement age by 1 year and 3 months (1.25 years). The mass of active workers $N^{W}$ thus mechanically grows by $3 \%$. The actual increase in employment also depends on the induced change in the employment rate $n$, giving total employment of $L=n p^{r} N^{W}$. Abstracting from other aging shocks, the increase in the workforce $N^{W}$ is offset by a decline in the mass $N^{R}$ of retirees. Working longer means spending less time in retirement so that fewer people claim benefits.

\footnotetext{
${ }^{17}$ Using OECD data, we found a correlation of 1.03 between statutory and average retirement ages. One can thus reasonably expect that raising the state pension age by 1 year will increase effective retirement by about one year, e.g. from 62 to 63 . Assuming work begins at age 18, this implies that the stationary workforce increases by about $1 /(62-18)=2.3 \%$.
} 
The DSGE model captures the macroeconomic and fiscal effects by reducing the transition rate from work to retirement, coupled with an offsetting increase in the mortality rate to keep population constant. In reality, mortality rises with age so that later retirement indeed raises the average mortality rate in the old group.

Spending Review (CUTS): The introduction argued that numerous tax deductions erode the income tax base in Austria by about a quarter, adding to complexity and reducing tax transparency. Specifically, we assume that such deductions ('tax expenditure') can be reduced from 25 to $20 \%$ of the true wage tax base without compromising distributional and other objectives. Broadening the tax base yields extra revenue that is used to reduce highly distorting marginal tax rates. Apart from reaping such efficiency gains, the government most likely could also achieve cost savings in supplying public services worth 0.5\% of GDP (reducing public consumption spending from 19.3 to $18.8 \%$ of GDP) without harming growth. Cutting 'unproductive' spending similarly allows to reduce highly distorting marginal tax rates and thereby yields a further growth stimulus.

\subsubsection{Reform Based Consolidation}

The passive approach merely scales up tax rates in the early consolidation phase to bring back the debt to GDP ratio to where it was prior to the Covid crisis. In the absence of reform, and with the long-run debt ratio being the same, the economy thus converges back to the pre-Covid stationary equilibrium. The green lines in Figure 4 illustrate this case. They end up with the long-run effects reported in column 'ISS' of Table 1. If consolidation is combined with efficiency improving reform, the economy moves to a new equilibrium as portrayed by the remaining columns. They report the cumulative effects, i.e. column RET refers to the impact of raising the retirement age on top of VAT and corporate tax reform (ACE), and column CUTS shows the impact of all reforms together. The upper part of Table 1 lists absolute values, the lower part gives changes in percent relative to the base case of passive consolidation. In all cases, the government targets the same long-run 
debt to GDP ratio of $71.25 \%$ annually, equal to the value prior to the Covid crisis. ${ }^{18}$ The final good is internationally traded at a fixed world price that is normalized to one.

Value Added Tax Reform (VAT): Consumption taxes drive a wedge between consumer and producer prices. VAT distortions thus inflate consumer prices and reduce value added prices. In bringing the reduced tax rate to the normal level, VAT reform slightly raises the consumer price index equivalent to a one time inflation of $1.8 \%$.

Moving to full refunding of input taxes strengthens producer prices (value added prices). Due to input output linkages, producer prices rise in both intermediate sectors, but more so in the tax favored sector which is directly affected by the reform. In the end, prices in both sectors and, in turn, the value added price $p^{v}$ are exactly 1 , equal to the net of tax price of the internationally traded final good which is fixed on world markets. Investment uses the final good. A rising value added price relative to a constant final goods price boosts investment incentives. The reform thus leads to capital accumulation by $4.8 \%$ in the long-run which strengthens labor productivity. The gross wage picks up by 4\%. Even though consumer prices increase, the capital induced wage effect dominates and yields larger real wage gains. Making work more attractive relative to inactivity reduces the unemployment rate by 0.8 percentage point which translates into an employment gain of $0.82 \%$. National income is defined as $Y=p^{v} Y^{v}$ (see 11, adjustment costs are zero in a steady state). VAT reform thus leads to a GDP expansion of $4.6 \%$ in the long-run which results from a $1.5 \%$ higher value added output due to increased factor use, and a $3.3 \%$ increase in the effective value added price due to the productivity gains from eliminating input distortions. This productivity gain is unique to the VAT reform and will not play out in other scenarios. The substantial income gains stimulate consumption by $1.4 \%$.

Moving to full refunding of input taxes leads to a fall in VAT revenue. Raising the reduced rate partly compensates. On net, VAT revenue declines by about $10 \%$ in the

\footnotetext{
${ }^{18}$ The model is implemented in quarterly frequency. The debt ratio relative to quarterly GDP would be $285 \%(4 \times 71)$. The world interest rate is $2 \%$, or $0.5 \%$ per quarter. Due to residence based interest taxation, the net of tax interest is $1.489 \%$ annually, or $0.372 \%$ quarterly. The marginal return on capital includes the depreciation rate.
} 
Table 1: Reform based consolidation, long-run effects

\begin{tabular}{|c|c|c|c|c|c|c|}
\hline Symbols & Names & ISS & VAT & $\mathrm{ACE}$ & RET & CUTS \\
\hline$t_{s}$ & Tax scaler & 1 & 1.0046 & 1.0215 & 0.9677 & 0.9199 \\
\hline$i_{n}$ & Net of tax interest $*$ ) & 1.4889 & 1.4866 & 1.4782 & 1.5049 & 1.5286 \\
\hline$F_{K}$ & Marg.prod.capital *) & 15.896 & 15.399 & 14.505 & 14.457 & 14.418 \\
\hline$D / Y$ & Debt/gdp ratio $*$ ) & 0.7125 & 0.7125 & 0.7125 & 0.7125 & 0.7125 \\
\hline$T / Y$ & Tax/gdp ratio & 0.4541 & 0.4317 & 0.4242 & 0.3969 & 0.3863 \\
\hline$p_{v}$ & Value added price & 0.9681 & 1 & 1 & 1 & 1 \\
\hline$P_{c}$ & Consumer price & 1.1804 & 1.2009 & 1.2043 & 1.1935 & 1.184 \\
\hline$n$ & Employment rate & 0.93 & 0.9376 & 0.9394 & 0.9485 & 0.9567 \\
\hline$Y$ & GDP & 0 & 4.8707 & 6.7181 & 10.39 & 11.259 \\
\hline$K$ & Capital stock & 0 & 4.8059 & 13.224 & 17.503 & 18.754 \\
\hline$L$ & Employment & 0 & 0.8209 & 1.0132 & 5.1416 & 6.0545 \\
\hline$C$ & Aggregate consumption & 0 & 1.3695 & 2.1982 & 5.8254 & 7.521 \\
\hline$w$ & Gross wage & 0 & 4.0169 & 5.6477 & 4.9916 & 4.9074 \\
\hline$T$ & Total Tax Rev. & 0 & -0.2825 & -0.2988 & -3.5071 & -5.3391 \\
\hline$T_{v}$ & VAT revenue & 0 & -10.109 & -7.8498 & -9.604 & -12.689 \\
\hline$T_{k}$ & Corporate tax rev. & 0 & 5.4054 & -21.796 & -23.74 & -27.236 \\
\hline$G_{B}$ & Social benefits & 0 & -0.7985 & -0.9343 & -7.0447 & -8.4383 \\
\hline
\end{tabular}

Absolute values in upper part, percent changes in lower part. The net of tax safe interest for savers is $i_{n}=100\left(1-\tau_{s}\right) i$. *) Annualized values, returns in $\%$.

long-run. However, the overall fiscal impact is negligible as the gains to GDP and employment improve the finances elsewhere. In addition, social spending declines by about $0.8 \%$ on account of the unemployment rate being reduced by 0.8 percentage points. The government may thus keep tax rates roughly constant. The pronounced growth effect swells all tax bases so that the same rates would yield higher revenue and roughly com- 
pensate for the revenue losses from moving to full deduction of input taxes in the tax exempt sector. Keeping other spending (public consumption and pension benefits) constant, the government in fact needs no more tax revenue for these reasons. Coupled with a pronounced GDP gain, the tax ratio falls by roughly 2 percentage points.

The long-run results might paint a too optimistic picture about reform based consolidation because the growth dividend is slow to arrive. The productivity gains from capital accumulation take a prolonged time to fully materialize. The need to bring down the debt to GDP ratio requires initially higher taxes. It is thus important to look at the entire transition. Figure 5 illustrates post-Covid developments for 200 quarters (50 years) after the crisis. All time series start in period 10 when the Covid shock is over. The straight lines in red indicate the values at the end of the Covid shock. The blue lines plot the base case with a passive consolidation policy. As mentioned before, the passive approach makes the economy converge back to the pre-Covid stationary equilibrium. The green line depicts the dynamics when passive consolidation is augmented by VAT reform. After full convergence, ${ }^{19}$ the changes relative to the pre-Covid equilibrium correspond to column VAT in Table 1. For example, GDP is $4.6 \%$ larger. The VAT reform yields immediate productivity gains, leading to an immediate gain in GDP. Although this swells tax bases, the direct revenue losses of VAT reform require about the same level of tax rates during the entire transition compared to the base case of passive consolidation (the green line is almost identical to the blue one in Figure 5).

Corporate Tax Reform (ACE): The differential effect of introducing an allowance for corporate equity (ACE) is seen by comparing to column VAT. Table 1 reveals two key direct effects. First, making the cost of equity tax deductible eliminates the tax wedge on investment and thereby reduces the required gross return on capital by almost one percentage point. With capital relatively cheaper, firms move to more capital intensive production which leads to an investment led expansion. The capital stock rises by 8.4 percentage points relative to the VAT scenario, and by $13.2 \%$ in total. It thereby

\footnotetext{
${ }^{19}$ Both overlapping generations and very slow debt consolidation lead to very slow convergence.
} 

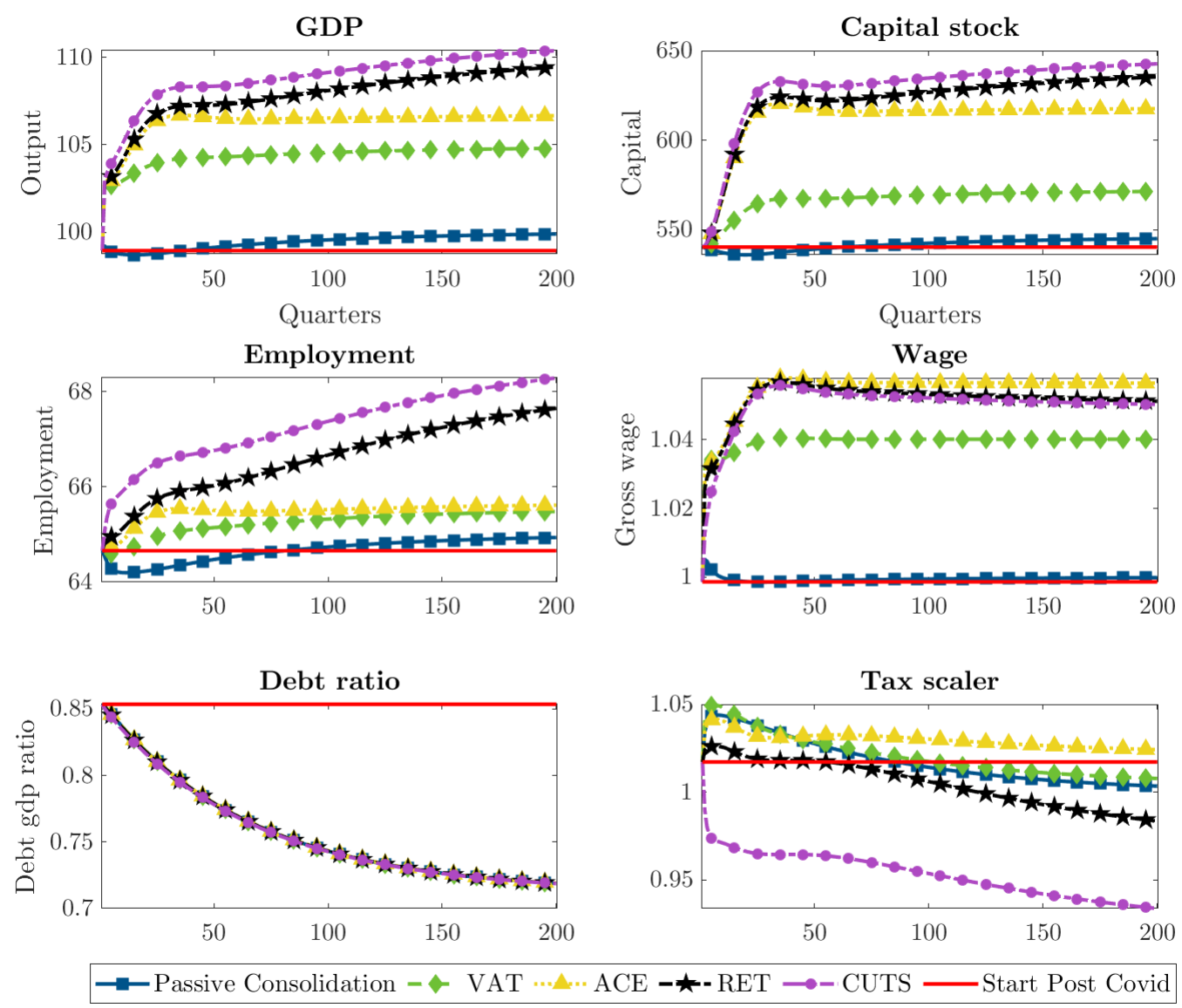

Figure 5: Reform based consolidation, dynamic effects

strengthens labor productivity and gross wages and weakly stimulates employment. In total, the reform adds almost two percentage points of GDP in the long-run. Second, however, corporate tax revenue shrinks by roughly a quarter. While the normal return on capital is fully tax deductible, the government is still able to collect substantial revenue from taxing excess returns reflecting rents from know-how, entrepreneurship, monopolistic profits and other sources not directly related to capital accumulation. Nevertheless, the loss in corporate tax revenue forces the government to scale up tax rates even though the induced expansion swells tax bases and strengthens the tax yield. The need to finance the revenue losses counteracts the growth effects to some extent. For example, higher wages stimulate employment, higher taxes reduce it which leaves a very moderate increase in 
employment on net.

Figure 5 illustrates the dynamic effects. Comparing the yellow and green lines shows the differential effect of the ACE reform, with the yellow line giving the total, cumulative effect compared to the base case equilibrium. The upper two panels illustrate the pattern of investment led expansion. The moderate gain in GDP is driven by a large increase in the capital stock. The last panel shows the intertemporal tax shifting that results from the delayed losses in corporate tax revenue when the notional interest deduction is limited to new equity. Figure 6 plots the index of corporate and other tax revenue to highlight this pattern. Initially, corporate tax revenue is strong since the stock of eligible equity capital is zero at the start. Investment neutrality also requires to cancel investment tax credits as part of the reform which initially even increases the corporate tax yield. Revenue strongly declines thereafter as eligible equity capital accumulates and an increasingly larger part qualifies for interest deductions. Since the government chooses a target path for primary surpluses, more corporate tax requires less other tax revenue initially.

The stock of eligible equity grows larger over time. After 16 quarters, corporate tax revenue starts to fall below initial levels and must be made up with other tax revenue to achieve consolidation. The tax scaler in Figure 5 thus falls below the VAT scenario in an initial phase when corporate tax revenue is high. When the loss in corporate tax revenue becomes larger, the government must scale up tax rates more strongly relative to the VAT scenario. As a result, the benefits of consolidation arrive faster since the tax burden is partly shifted to future periods. Given the small share of corporate tax in overall tax revenue, the effect is not particularly powerful. Nevertheless, the ACE reform succeeds to combine an immediate and strong growth stimulus with a delayed loss in tax revenue, thereby facilitating the early phase of fiscal consolidation.

Postponed Retirement (RET): In the long-run, an increase in the effective retirement age by one year and three months implies a $3 \%$ larger workforce $N^{W}$. With no other change in population size, the group of retirees is correspondingly smaller. Given the mechanical change in the dependency ratio, the budget simultaneously improves on 


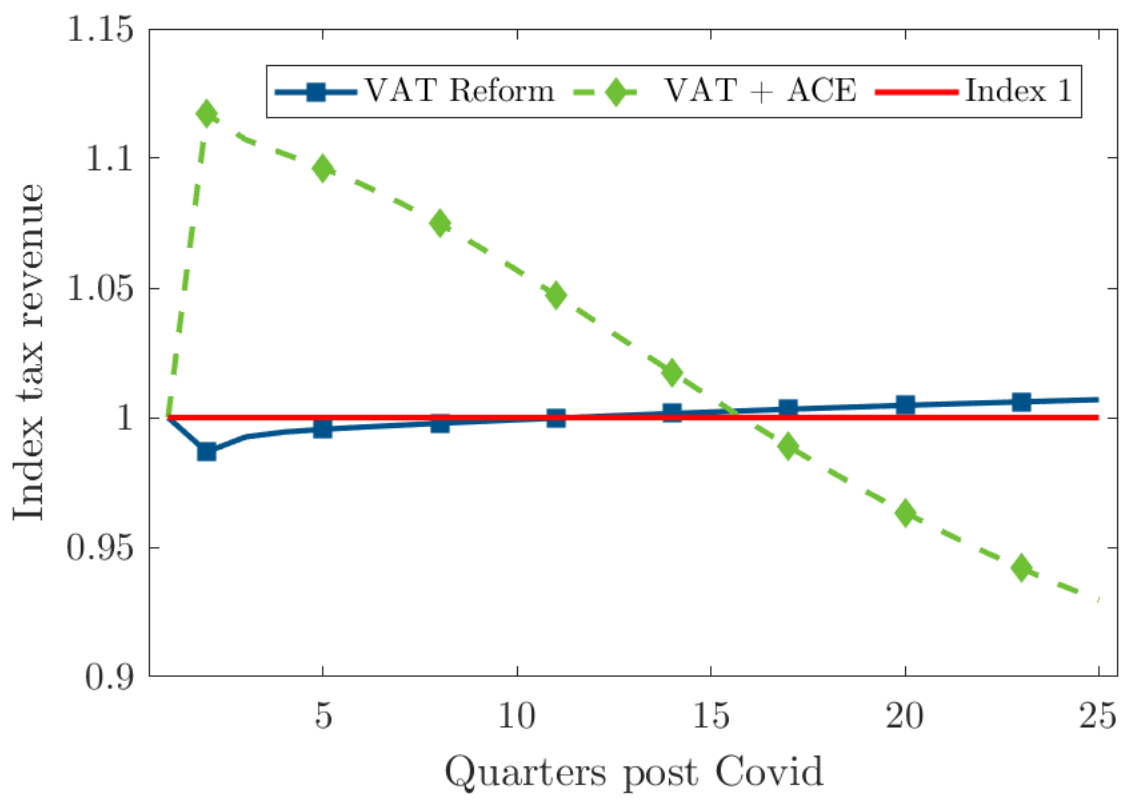

Figure 6: Index corporate and other tax revenue

two margins: wage tax and contribution revenues increase while pension spending falls. The budget effects are bound to be very powerful, leading to a significant cut in marginal tax rates across the board, fuelled by large savings in social spending due to lower pension payments and a higher employment rate in the active age group. Note that these savings merely reflect employment gains and are not due to cutting any individual entitlements. Per capita pension payments and social transfers remain unchanged. Over a full life-time, however, an increase in retirement age reduces total pensions received and brings them closer to total contributions paid, thereby moving the insurance scheme to increased actuarial fairness. In Table 1, social spending is down by $6.1 \%$ relative to the ACE scenario, or $7 \%$ in total.

With expanding tax bases and large savings in social spending, the government affords to scale down marginal tax rates across the board. The more favorable tax climate relative to the ACE scenario triggers substantial behavioral effects on labor supply and investment. The capital stock expands by an additional four percentage points and the employment rate among active workers rises by almost 1 percentage points. Together with 
the demographic increase in the active workforce, employment expands by an additional 4\%, making the total employment gain 5.1\% relative to the base case. Employment and investment responses let GDP grow by an additional 3.6 percentage points on top of the gains from other reforms, giving a total GDP gain of $10.4 \%$. The large income gains translate into large gains in consumption. The savings in social spending require less tax revenue so that the tax to GDP ratio declines from 45.5 to $39.7 \%$.

Figure 5 illustrates the dynamics of raising the retirement age. Apart from a longer transition period and a larger quantitative impact, the qualitative results are similar to the other scenarios. Protecting pension entitlements promised to older generations prior to the policy change requires a slow phasing in of the mandated increase. We capture the macroeconomic consequences by a slow and delayed increase in the transition rate into retirement. Replacing old generations by young ones takes a long time. Together, slow demographic change and delayed phasing in substantially prolongs the transition phase. Given the physical increase in the workforce, the long-run GDP gain is large compared to other policy reforms in Figure 5. However, these gains take a long time to materialize. The GDP gain is mainly driven by employment growth which is supported by a parallel expansion of the capital stock.

Spending Review (CUTS): The last element of the reform based strategy are cuts in 'unproductive' spending on public consumption worth $0.5 \%$ of GDP, and a reduction of tax deductions from 25 to $20 \%$ of the true wage tax base. Given the same long-run debt to GDP target, these policy measures allow further cuts in distorting marginal tax rates financed with non-distorting expenditure cuts. The tax scaler drops instantaneously from about 1.02 to 0.98 , leading to substantial reductions in all marginal tax rates. The income tax rate, for example, would drop by 1 percentage point right at the start of the post-Covid era. ${ }^{20}$ Effects are significant, leading to an additional 0.9 percentage points in

\footnotetext{
${ }^{20}$ In total, tax rates could be scaled down by a factor of 0.92 in the long-run. The wage tax rate, for example, could be lower by 3 percentage points (from $32 \%$ at the end of the Covid crisis to $29 \%$ in the long-run), and the rate cuts set in quite fast. Corporate and value added tax rates would decline by 1 to 2 percentage points. Personal income tax rates on savings get reduced by the same factor which raises
} 
GDP. Owing to larger disposable income, aggregate consumption is 1.9 percentage points higher in the long-run.

The last column in Table 1 and the violet lines in Figure 5 report the cumulative, total effects of the reform based consolidation strategy. To sum up, the quantitative results point to the possibility that a reform based fiscal strategy could succeed to consolidate the Covid debt without raising marginal tax rates or cutting per capita social entitlements. Implementing ambitious tax and pension reform could reap substantial efficiency gains to ease the burden of debt consolidation. The debt to GDP ratio could decline as a result of strong growth rather than fiscal savings resulting from tax increases or expenditure cuts. A passive strategy, in contrast, must scale up tax rates in the near future to bring down the debt to GDP ratio at the cost of current generations which could possibly create political resistance among today's voters. A reform based strategy, in contrast, could bring down tax rates quite significantly and right after the end of the Covid crisis, thereby benefiting current generations for the rest of their life. Future generations would fare even better, inheriting a richer economy with a lower debt to GDP ratio.

\subsubsection{Sensitivity Analysis}

Consolidation Speed: We have estimated the speed of budget consolidation $\nu=0.985$ which is very close to an approximation of Maastricht debt reduction rules. The fiscal policy rule (22) thus implies rather slow consolidation which stretches the Covid burden far into the future. The half-life of consolidation is 45 quarters or about 11 years. $^{21}$ In other words, it takes about 11 years until half of the Covid debt is repaid. The relatively slow consolidation also implies slow economic convergence. We contrast this the (annualized) net of tax interest on safe assets from 1.49 to $1.53 \%$, or 0.4 percentage points. The world interest is fixed in a small open economy. The residence principle of interest taxation thus implies that the domestic net of tax interest on personal savings could slightly increase.

${ }^{21}$ Without shocks, the policy rule $(22), d_{t}=\nu d_{t-1}+(1-\nu) \bar{d}$, solves for $d_{t}=\nu^{t} \cdot d_{0}+\left(1-\nu^{t}\right) \cdot \bar{d}$. Half of convergence is complete if $d_{t}-\bar{d}=\frac{1}{2}\left(d_{0}-\bar{d}\right)$. Substituting for $d_{t}$, the half-life of adjustment is thus determined by $v^{t}=0.5$, giving $t_{1 / 2}=\log (0.5) / \log (\nu)$. 
scenario with a more ambitious goal of eliminating the Covid debt faster. Setting the auto-regressive coefficient to $\nu \approx 0.966$ implies fast consolidation with a half-life of only 5 years or 20 quarters. The government must thus consolidate more aggressively early on by levying higher taxes to achieve larger surpluses. Economic convergence is much faster but eventually approaches the same long-run equilibrium as in Table 1 (full policy reform, column CUTS). Figure 7 illustrates the trade-off with the blue lines referring to slow consolidation, and the green ones indicating faster consolidation.

The higher tax rates required in the early phase impair incentives for employment and investment. However, a more ambitious approach reduces the debt ratio faster and unleashes the full growth effects of reform based consolidation earlier. Economic performance lags in a first phase before it overtakes performance under delayed consolidation. Overtaking occurs after about 40 quarters or roughly 10 years. Faster consolidation thus imposes a larger burden on generations living immediately after the end of the Covid crisis to the benefit of future generations born after the first adjustment phase. Generations born in the distant future near the new stationary equilibrium are not affected since policy differences only affect the timing of the transition.

Behavioral Parameters: Given the inherent uncertainties in estimating and calibrating a DSGE model, it is important to explore the sensitivity and robustness of results with respect to key parameters. Column Q4 in Table 2 shows the results of such sensitivity analysis four quarters after the end of the Covid shock. The lines 'Base Case' repeat the results of reform based consolidation in the preceding sections. Column FSS repeats the numbers in Table 1 with output, for example, rising by $11.3 \%$ in the long-run, and employment by $6 \%$.

How do results change when job search and employment react more elastically? In the base case calibration, the semi-elasticity of job search with respect to a one percent wage increase is 0.4 , i.e., the employment rate would rise by 0.4 percentage points. The lines 'Elastic LS' report the effects of the same policy intervention when job search responds more elastically with a semi-elasticity of 0.6. A high elasticity obviously works as a 

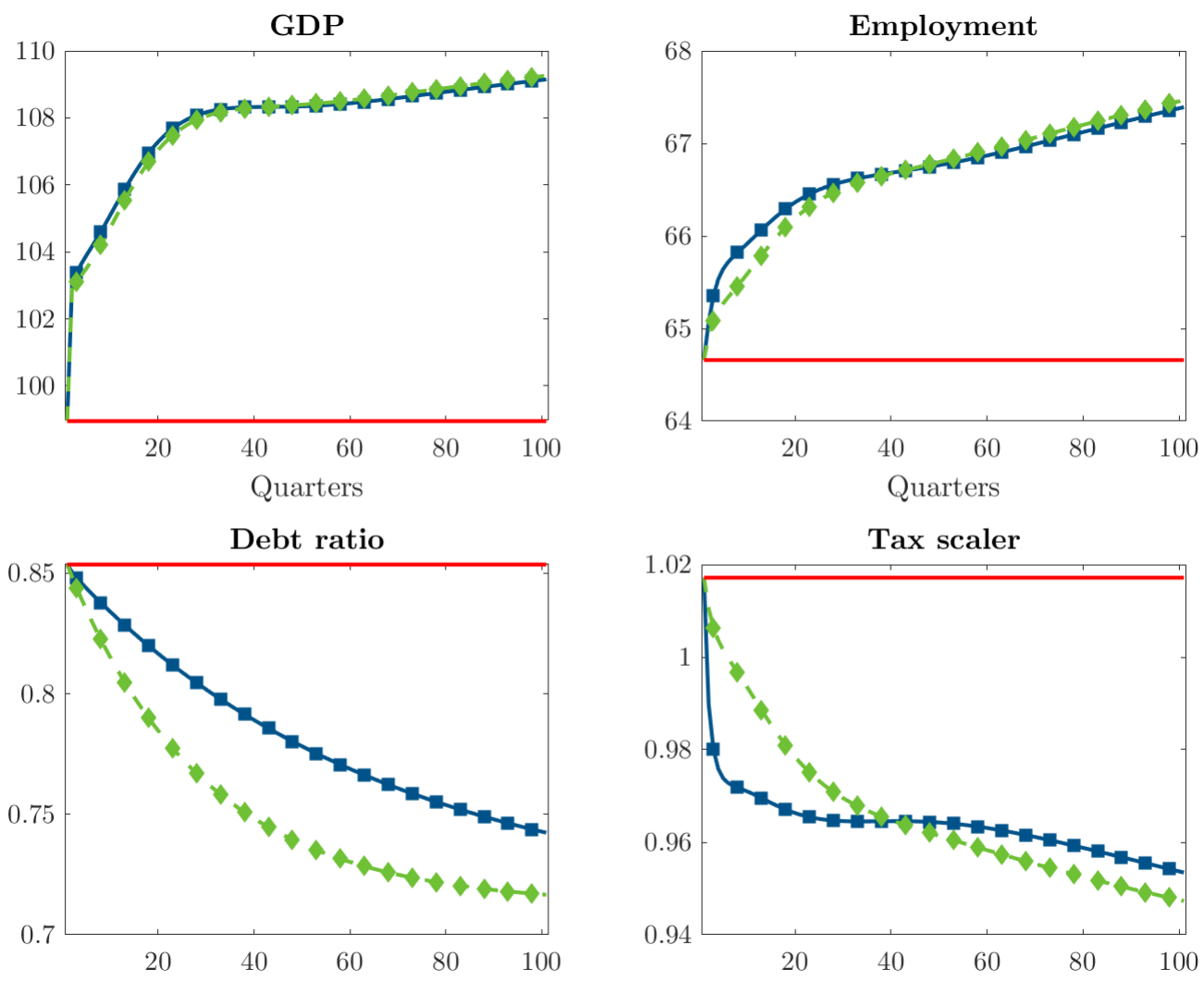

$\rightarrow$ Full reform, slow consolidation $-\downarrow$ Fast consolidation $—$ Start Post Covid

Figure 7: Speeding up fiscal consolidation 
magnifier, with a significant quantitative impact. In the long-run, output rises by $12.4 \%$ which is 2 percentage points more than in the base case, and employment grows by 7.3 instead of $6 \%$. Due to adjustment costs, firms can raise employment only with some delay so that employment gains are slow to set in. But the stronger response is already felt in the fourth quarter when the consolidation policy is fully enacted at the end of the Covid pandemic. The same holds for tax rates. In our model, the government already started to counter the large increase in public debt prior to the end of the crisis, even though the major part of temporary deficits were debt financed. Figure 7 thus shows that, at the end of the Covid crisis, tax rates exceeded historical values by a factor of 1.02 . The ambitious consolidation policy reduces tax rates right after the end of the crisis, and slightly more so when job search is more elastic. The more vigorous expansion swells tax bases and yields more revenue so that tax rates may be scaled down substantially more in the long-run, by a factor of 0.9 instead of 0.92 .

Moving to an ideal VAT with full deductions of tax on intermediate inputs works like a productivity increase and yields surprisingly large efficiency gains. Our macroeconomic model captures sector linkages only in a very stylized way which could introduce some uncertainty in quantitative results. The base case calibration set the depth of the supply chain to $\xi=0.32$ and the demand share of the tax privileged sector to $\phi=0.19$, suggested by Austrian data. We recompute the effects of debt consolidation with substantially lower VAT distortions by reducing parameters to $\xi=0.2$ and $\phi=0.1$. The lines 'Harmless VAT' in Table 2 report results. In this case, moving from the status quo to an 'ideal VAT' with full deduction of input taxes yields considerably smaller output gains of 8.3 instead of $11.3 \%$, which is three percentage points less compared to the base case. Employment gains are lower but rather insignificantly so. The reason is that the direct budget costs of allowing full deduction of input taxes in sector 1 are smaller in this case. In the end, tax rates can be cut down rather more in this case which partly offsets the employment losses due to reduced productivity gains.

Finally, we explore the effects of debt consolidation without implementing and ACE 
Table 2: Debt Consolidation, Sensitivity Analysis

\begin{tabular}{|c|c|c|c|c|c|}
\hline Output & Q4 & Q8 & Q20 & $\mathrm{Q} 40$ & FSS \\
\hline Base Case & $3.90 \%$ & $4.85 \%$ & $7.43 \%$ & $8.33 \%$ & $11.26 \%$ \\
\hline Elastic LS & $4.21 \%$ & $5.42 \%$ & $8.40 \%$ & $9.40 \%$ & $12.42 \%$ \\
\hline Harmless VAT & $1.67 \%$ & $2.46 \%$ & $4.57 \%$ & $5.37 \%$ & $8.34 \%$ \\
\hline No ACE & $3.70 \%$ & $4.19 \%$ & $5.54 \%$ & $6.26 \%$ & $9.63 \%$ \\
\hline Employment & Q4 & Q8 & Q20 & $\mathrm{Q} 40$ & FSS \\
\hline Base Case & $0.99 \%$ & $1.34 \%$ & $2.15 \%$ & $2.60 \%$ & $6.05 \%$ \\
\hline Elastic LS & $1.44 \%$ & $2.11 \%$ & $3.26 \%$ & $3.79 \%$ & $7.37 \%$ \\
\hline Harmless VAT & $0.88 \%$ & $1.24 \%$ & $1.96 \%$ & $2.41 \%$ & $5.98 \%$ \\
\hline No ACE & $0.83 \%$ & $1.09 \%$ & $1.65 \%$ & $2.18 \%$ & $5.96 \%$ \\
\hline Tax Scaler & Q4 & Q8 & Q20 & $\mathrm{Q} 40$ & FSS \\
\hline Base Case & 0.9739 & 0.9714 & 0.9660 & 0.9646 & 0.9199 \\
\hline Elastic LS & 0.9649 & 0.9588 & 0.9498 & 0.9478 & 0.9029 \\
\hline Harmless VAT & 0.9606 & 0.9576 & 0.9523 & 0.9500 & 0.9046 \\
\hline No ACE & 0.9803 & 0.9769 & 0.9687 & 0.9603 & 0.9026 \\
\hline
\end{tabular}

Notes: Elastic LS - high search elasticity; Harmless VAT: distortions reduced; No ACE: consolidation without ACE reform.

corporate tax reform. Introducing an allowance for corporate equity might yield considerable growth effects but also entails a substantial loss in tax revenue. ${ }^{22}$ Line 'No ACE' in Table 2 reports the effects of consolidation when corporate tax reform is not included.

\footnotetext{
${ }^{22}$ Fundamental tax reform proposals such as the Mirrlees review recommend moving to an ACE tax. Such reform promises more growth thanks to investment neutrality but also more financial stability by eliminating the tax bias in favor of debt. Financial stability gains are not captured by our model.
} 
Output gains are lower by 1.6 percentage points in the long-run, compared to the base case, and employment gains are more moderate as well. The losses are dampened by the fact that this case avoids the losses in corporate tax revenue and thereby allows a larger reduction in all tax rates (including the corporate tax rate). Rates are scaled down by a factor of .9 instead of .92 in the long-run. However, immediately after the start of the policy change, tax rates must be slightly higher relative to the base case. The reason is that limiting ACE deductions to new equity promises immediate growth effects but delays the losses in tax revenue. However, given the relatively small share in total tax revenue, the inter-temporal shifting of tax revenue is quantitatively not important. In all three cases, the qualitative predictions of our analysis on consolidating the Covid debt remain unchanged.

\section{Conclusions}

The key idea behind the 'reform based consolidation strategy' is to reap unexploited efficiency gains and implement growth oriented reforms that would make sense even without any need for consolidation. If a country can enjoy a significant 'growth dividend', fiscal consolidation would be less painful and politically easier, if unfavorable distributional consequences can be controlled for. The simulations suggest that consolidation of the Covid debt combined with fundamental policy reform could boost GDP by about 11\% and reduce the tax to GDP ratio by almost 7 percentage points, compared to current trends. The increase in the debt to GDP ratio caused by the Covid crisis is reversed and brought back to the current level without cutting individual benefit entitlements or raising headline tax rates. Considering the entire transition period shows that tax rates could be reduced right from the beginning if fiscal consolidation proceeds slowly and is stretched over many periods. A more ambitious strategy for a faster reduction of the Covid debt, however, must achieve higher fiscal surpluses today which reduces the gains of current generations to the benefit of future ones. 


\section{A Appendix: Estimation and Parameter Values}

Most of our structural parameters have been obtained directly by means of calibration to match specific data and from standard values and consensus estimates in existing research. However, we have jointly estimated some key parameters based on historical data. The most important of these are $\nu$, the speed of convergence for excess government debt, and $\rho_{t}$, the degree of tax smoothing which play an important role in the policy simulations. We have also estimated the variances and auto-correlations of the shock variables of the model which allows us to perform stochastic simulations and estimate second moments to compare model performance with data and other models. This Appendix outlines data and methods used for estimation and calibration.

\section{A.1 Fiscal Data and Parameters}

Tax rates and key fiscal parameters relate to the stationary public sector budget prior to the Covid crisis, see section 4.1 for a very short overview. Capital income taxes are levied at the personal and firm level. The statutory corporate profit tax rate is $25 \%$, $\tau^{k}=.25$. Tax incentives for investment reduce the effective marginal tax rate which we capture by an investment deduction of $\tau^{I}=0.05$. At the investor level, Austria levies a comprehensive flat rate of $25 \%$ on interest, dividends and capital gains. We thus set $\tau^{s}=.25$ relating to taxation of interest and dividends. The residence principle of interest taxation implies that the gross interest rate is fixed on world markets, $i^{*}=.005$ quarterly or $2 \%$ annually. The net of tax interest $\left(1-\tau^{s}\right) i^{*}$ governing national savings is endogenous to the domestic interest tax. Since capital gains are taxed only upon realization, the effective tax rate is reduced by interest gains on unrealized capital gains. We thus set $\tau^{g}=.15$. We assume that dividends include a marginal component fluctuating with firm performance and a constant basic dividend which introduces some inertia in payouts. Assuming a marginal payout ratio of $\theta=0.5$ gives an average tax rate on equity returns

of $\tau^{e}=\theta \tau^{s}+(1-\theta) \tau^{g}$. Our assumptions imply that the dividend tax partly distorts 
investment by making external equity financing more expensive.

In modeling the VAT, we set $\tau^{v}=0.2$ equal to the standard VAT rate. The reduced rate $\tau^{1}=0.1$ in the tax favored sector 1 is an average of rates applying to different goods, ranging from zero to the standard rate. VAT distortions result from tax exempt sectors being denied deduction of the VAT on inputs. Data from the most recent 2017 input output tables (Statistik Austria, 2021a) yield a demand share $\phi=0.189$ for output of the tax favored sector 1. By the same source, the share of intermediate inputs in gross output is $\xi=0.321$. Having set all other tax rates, we compute the average labor income tax rate to match total tax revenue, giving a rate of $\tau=0.31$.

Turning to the expenditure side, data from Austrian national accounts (Eurostat, 2021, series namq_10_gdp) give a Hamilton-filtered trend value for government consumption $G$ equal to $19.3 \%$ of gdp. To pin down social spending, we need employment and population structure. We normalize the gross wage rate to $w=1$ and get employment $L$ to support the labour share $1-\alpha-\bar{\alpha}$ in value added income, see Table A.1 below. Data from Statistik Austria (2021d) give an unemployment rate of $7 \%$ and a participation rate of $74 \%$ in 2019. These values correspond to the LUK definition of unemployment in the Austrian annual microcensus, which asks individuals to class themselves as employed, unemployed or inactive. This is slightly below the official Austrian rate of $7.4 \%$ and above the $4.5 \%$ obtained using the standard ILO definition. Given these rates, we compute the size $N^{W}$ of the young age group to support aggregate employment, $L=n p^{r} N^{W}$.

World Bank data give a dependency ratio of is $N^{R} / N^{W}=0.286$ from which we deduce the size of the old age group. Using aggregate mortality data and the dependency ratio, we impute a transition rate $\omega=0.9904$ from work into retirement, a stationary inflow $N^{n}=(1-\omega) N^{W}$, and a matching outflow $(1-\gamma) N^{R}=N^{n}$ to keep population size constant. The implied survival rate in the old age group is $\gamma=0.9663$. Regarding social spending, we set the replacement rate in unemployment insurance $\bar{b}^{l}=0.55$ which was the applicable rate for workers on the median salary in 2019. Value at median wage is $55 \%$ as of 2019 OECD (2021b). The per capita state pension $b$ of retirees is computed to 
match aggregate pension expenditure $b N^{R}$ equal to $12 \%$ of gdp which implies an average replacement rate of $60 \%$. In addition, we specify unconditional social transfers $b^{w}$ and $b^{r}=0.6 b^{w}$ per capita of young and old age groups and scale them to match social spending other than pensions and unemployment insurance benefits. Finally, we set the level of sovereign debt equal to $71.25 \%$ of annual gdp which is the 2019 level prior to the Covid crisis and gives a stationary target ratio of $\bar{d}=2.85$ relative to quarterly gdp.

\section{A.2 Key Behavioral and Structural Parameters}

Table A.1 reports the most important structural and behavioral parameters. Unless specified otherwise, values are standard in the literature.

Table A.1: Behavioral and Structural Parameters

\begin{tabular}{clll}
\hline Par. & Interpretation & Value & Source \\
\hline$i^{*}$ & Quart. world interest & 0.5 & $2 \%$ annual rate \\
$\bar{r}^{e}$ & Quart. equity return & 1.82 & $7.5 \%$ annual rate \\
$\sigma$ & Intertemp. elasticity & 0.63 & Groom and Maddison $(2019)$ \\
$\eta$ & Search elasticity & 0.4 & Whalen and Reichling $(2017)$ \\
$\alpha$ & Compet. capital share & 0.21 & $40 \%$ of $35 \%$ share \\
$\bar{\alpha}$ & Income share rents & 0.14 & $60 \%$ of $35 \%$ share \\
$\delta$ & Depreciation rate & 2.41 & $10 \%$ annual rate \\
$b^{k}$ & Debt asset ratio & 0.66 & Beer and Waschiczek $(2019)$ \\
\hline
\end{tabular}

Appealing to longer-term average, we take world interest to be $2 \%$ per anno, and refer to Jordà et al. (2019) for the long-term annual return on equity of $7.5 \%$, including an equity premium. Referring to Whalen and Reichling (2017), we use a semi-elasticity of job search with respect to the gross wage of 0.4 . On the production side, the capital income share reflects a competitive and monopolistic component. With $21 \%$ of value added income, the competitive capital income share is at the rather low end while the 
total share of $35 \%$ is on the high end. The depreciation rate is standard. Finally, Beer and Waschiczek (2019) find an average share of equity in total assets of $34 \%$ for Austrian non-financial firms which gives a debt asset ratio of 0.66 .

\section{A.3 Estimation}

To allow estimation, the model includes shock processes for total factor productivity, $a_{t}=(1-\rho) \bar{a}+\rho a_{t-1}+\sigma^{a} \epsilon_{t}^{a}$; shocks $i_{t}=\left(1-\rho^{i}\right) i^{\star}+\rho^{i} i_{t-1}+\sigma^{i} \epsilon_{t}^{i}$ to the gross domestic interest rate which fluctuates along with the world interest rate $i^{\star}$, and shocks to the fiscal consolidation policy $d_{t}=\nu d_{t-1}+(1-\nu) \bar{d}-\tilde{S}_{t} / Y_{t}^{a}+\sigma^{d} \epsilon_{t}^{d}$, leading to deviations from the target path of the debt to gdp ratio. Temporary deficits $\tilde{S}_{t}$ fully go into debt and are consolidated in later periods. We also assume that fiscal policy targets the ratio $d_{t}=D_{t} / Y_{t}^{a}$ of sovereign debt relative to potential output. Potential output is a slow moving average $Y_{t}^{a}=\rho^{y} Y_{t-1}^{a}+\left(1-\rho^{y}\right) \bar{Y}$ of past GDP realizations and stationary GDP equal to $\bar{Y}$. Potential output should adjust with the lowest adjustment speed of all its driving forces, leading us to set $\rho^{y}=0.975$. In addition, the model assumes policy inertia in tax rate adjustment $t^{s}=\rho^{t} t_{t-1}^{s}+\left(1-\rho^{t}\right) t_{t}^{n}$. The factor $t_{t}^{s}$ scales all marginal tax rates. A value of $t_{t}^{n}$ would be required to instantaneously balance the budget conditional on target debt. Since the actual tax scaler partly depends on last period's value, it changes only with delay, leading to temporary short-falls or excess amounts in tax revenue which contribute to temporary surpluses or deficits $\tilde{S}_{t}$ as discussed in (21).

For estimation purposes, we obtained data from Eurostat (2021) on gdp, investment, consumption, labor supply, government debt and nominal interest rates for 1997-2019. ${ }^{23}$ We omitted data from 2020 since we aim at pre-Covid structural values. Those series with a trend component were detrended using a Hamilton filter (Hamilton, 2018). The gdp deflator was imputed from the nominal and real GDP series, and was then used to transform nominal into real interest rates. We noted a substantial structural break in the

\footnotetext{
${ }^{23}$ Eurostat series "namq_10_gdp", "lfsq_egan", "gov_10q_ggdebt" and "irt_st_q".
} 
debt to gdp ratio following the financial crisis 2008-2009. For this reason, we chose to use the deficit/gdp rather than the debt/gdp ratio in estimating fiscal policy parameters.

Table A.2: Estimation Results

\begin{tabular}{|c|c|c|c|c|c|c|}
\hline Par. & Prior & Post. & $10 \%$ & $90 \%$ & Dist. & Pstdev \\
\hline$\psi^{I}$ & 2 & 2.0936 & 1.529 & 2.7041 & norm & 0.5 \\
\hline$\psi^{L}$ & 2 & 1.6448 & 0.9401 & 2.3136 & norm & 0.5 \\
\hline$\nu$ & 0.987 & 0.9848 & 0.9743 & 0.9942 & beta & 0.01 \\
\hline$\rho^{t}$ & 0.8 & 0.2327 & 0.1238 & 0.3265 & beta & 0.1 \\
\hline$\sigma^{a}$ & 0.006 & 0.0087 & 0.0071 & 0.0104 & gamm & 0.003 \\
\hline$\sigma^{d}$ & 0.02 & 0.0284 & 0.0218 & 0.0345 & gamm & 0.01 \\
\hline$\sigma^{i}$ & 0.008 & 0.0055 & 0.0047 & 0.0064 & gamm & 0.005 \\
\hline$\rho$ & 0.95 & 0.9081 & 0.8904 & 0.9253 & beta & 0.02 \\
\hline$\rho^{d}$ & 0.9 & 0.6865 & 0.5628 & 0.8252 & beta & 0.05 \\
\hline$\rho^{i}$ & 0.3 & 0.4851 & 0.4054 & 0.5629 & beta & 0.1 \\
\hline$C_{o b s}$ & 0.02 & 0.0099 & 0.0083 & 0.0115 & gamm & 0.01 \\
\hline$d_{o b s}$ & 0.01 & 0.0102 & 0.002 & 0.0179 & gamm & 0.005 \\
\hline$I_{o b s}$ & 0.02 & 0.0207 & 0.0167 & 0.0245 & gamm & 0.01 \\
\hline$L_{o b s}$ & 0.02 & 0.0134 & 0.0114 & 0.0153 & gamm & 0.01 \\
\hline$(w \times L)_{o b s}$ & 0.02 & 0.0162 & 0.0134 & 0.0194 & gamm & 0.01 \\
\hline$Y_{o b s}$ & 0.02 & 0.007 & 0.0041 & 0.0097 & gamm & 0.01 \\
\hline
\end{tabular}

Notes: "Prior" and "Post." refers to the means of the prior and posterior distributions respectively. $10 \%$ and $90 \%$ refer to the lower and upper bounds of the 90\% HPD interval. Pstdev refers to the standard deviation of the prior distribution. $X_{o b s}$ denotes the standard deviation of the measurement error associated with the observed $X$.

Using these data, we performed a Bayesian (Markov Chain Monte Carlo, MCMC) 
estimation of the adjustment costs $\psi^{L}$ and $\psi^{I}$ in Dynare, along with the fiscal smoothing parameters $\rho^{t}$ and $\nu$ and the shock variances and $A R(1)$ persistence for the technology, interest rate and deficit shocks $\epsilon^{a}, \epsilon^{i}$ and $\epsilon^{d}$. Following Pfeifer (2014), we assumed that any differences between our model and the observed data can be explained through measurement error shocks. We chose conservative priors with large standard deviations which reflect our uncertainty over what a plausible range might be for these parameters in a structurally complex model. The parameters $\psi^{I}$ and $\psi^{L}$ govern inertia in investment and hiring as discussed in (17). We used normal priors for these adjustment cost parameters since their values are unbounded. Furthermore, we assumed gamma distributions for shock variances and beta distributions for shock auto-correlations (where applicable) and fiscal adjustment $\nu$, making them appropriately bounded. Table A.2 reports the results of the estimation procedure.

It is worth briefly discussing the key features of this estimation. Firstly, we set the prior of the fiscal adjustment speed $\nu$ to 0.987 , implying excess debt must fall by onetwentieth each year during normal times. This is the slowest speed of adjustment which avoids intervention under the corrective arm of the Stability and Growth Pact (European Parliament, 2021). The posterior estimate of 0.9848 implies convergence is on average very slightly faster than this legal minimum but still relatively slow, with a half-life for excess debt of 45 quarters.

Secondly, the priors and posteriors for the adjustment cost parameters $\psi^{I}$ and $\psi^{L}$ both fall within the typical range of literature estimates. ${ }^{24}$ The $90 \%$ HPD intervals on these parameters is uncomfortably large, reflecting limited data availability and established difficulties in precisely estimating adjustment costs, but our results are not overly sensitive

\footnotetext{
${ }^{24}$ Estimates for $\psi^{I}$ vary substantially. Our estimate is below that of Christiano et al. (2005), but above those of Levin et al. (2005) and Groth and Khan (2010). There is much less econometric evidence of $\psi^{L}$ since there is no standard specification of labor adjustment costs akin to that for investment (Cahuc et al., 2014), but Cooper and Willis (2009) finds that $\psi^{L}=2$ 'is not unreasonable' on their econometric evidence, with substantial uncertainty. While our estimates are on the higher end of literature values, we consider this reasonable in the absence of habit persistence and other smoothing devices.
} 
to these parameters in any case. Thirdly, the tax smoothing parameter $\rho^{t}$ is rather low relative to our a priori expectations. This is partly explained by fairly high $\rho^{d}$ which also acts to slow the speed of fiscal adjustment, but also turns out lower than expected.

Overall, we believe the quality of the estimated parameters is perfectly good enough in our context. They only impact the transitional dynamics, and not the steady state. This means that our core results are robust to the uncertainty. It is also reassuring that where we estimate parameters with clear equivalents in the established literature or in theory such as $\psi^{I}$ and $\nu$, the estimated values lie close to our expectations.

\section{A.4 Calibrating the Covid shock}

We model the Covid pandemic as an exogenous shock to the utilisation rate of capital and labour. Households are compensated for the loss of wage income and firms for the loss of profits (but excluding rents, i.e., excess profits). In particular, we approximate the disease trajectory as a Gauss curve over nine quarters. This approach clearly oversimplifies the observed trajectory since in reality the pandemic had multiple peaks. Nonetheless, we thereby capture in a simple and tractable way the cumulative output loss and the emergence of the observed Covid debt.

We assert a 'standard deviation' of 1.5 quarters, which ensures that $99.7 \%$ of the impact occurs within our 9-quarter interval, and truncate the rest. We then optimize the height of the curve (and hence the total volume of the impact) to meet two targets: the cumulative loss of GDP and the total increase in fiscal debt. We obtain a GDP loss from the latest WIFO forecast for Austria (Glocker 2021) until the end of 2021, equal to $12.57 \%$ of annual GDP. The Austrian fiscal advisory council (Fiskalrat 2021) reports a 19.2\% increase in the debt to GDP ratio by the same date. To come close to these targets, we then minimise the square loss function Loss $=\log (\text { ModelLossOutput/TargetLossOutput })^{2}+$ $\log (\text { ModelDebtGDP/TargetDebtGDP })^{2}$. We use squared log ratios rather than squared differences so that the scale is comparable between the two targets. This procedure gives us a shock height of 0.166 , with the model predicting a cumulative output loss of $16.5 \%$ 
and an increase in debt of $14.0 \%$. Using this procedure, our parsimonious pandemic model somewhat overstates the actual output loss and understates the actual increase in debt.

\section{References}

A. Alesina, C. Favero, and F. Giavazzi. Effects of austerity: expenditure-and tax-based approaches. Journal of Economic Perspectives, 33(2):141-162, 2019.

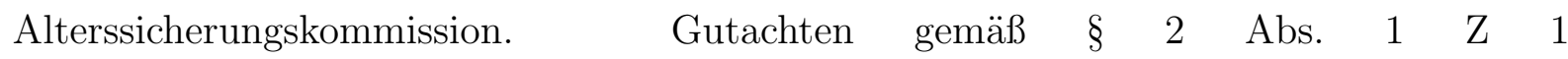
Alterssicherungskommissions-Gesetz, Teil: voraussichtliche Gebarung der gesetzlichen Pensionsversicherung in den Jahren 2021 bis 2026, 2021. URL https://www . sozialministerium .at/dam/jcr:b21032af-d6d4-4a2a-8dfda012567ac5a0/Mittelfristgutachten\%20gesetzliche\%20PV\%202021-2026.pdf.

D. Altig, A. J. Auerbach, L. J. Koltikoff, K. A. Smetters, and J. Walliser. Simulating fundamental tax reform in the United States. American Economic Review, 91(3):574595, 2001.

M. Ayaz, L. Fricke, C. Fuest, and D. Sachs. Who should bear the burden of COVID-19 related fiscal pressure? An optimal income taxation perspective. CESifo WP, 9420, 2021.

C. Bayer, B. Born, R. Luetticke, and G. J. Müller. The Coronavirus stimulus package: How large is the transfer multiplier? 2020.

C. Beer and W. Waschiczek. Equity ratios of Austrian non-financial corporations-evidence from balance sheet data. Monetary Policy and the Economy, (Q3/19):25-41, 2019.

R. Beetsma, O. Furtuna, M. Giuliodori, and H. Mumtaz. Revenue-versus spending-based fiscal consolidation announcements: Multipliers and follow-up. Journal of International Economics, 131:103455, 2021.

S. G. Benzell, L. J. Kotlikoff, and G. LaGarda. Simulating business cash flow taxation: An illustration based on the "Better Way" corporate tax reform. NBER Working Paper Series, No 23675, 2017.

O. Blanchard. Debt, deficits, and finite horizons. Journal of political economy, 93(2): 223-247, 1985.

R. Boadway and N. Bruce. A general proposition on the design of a neutral business tax. Journal of Public Economics, 25:231-239, 1984.

S. Boeters, C. Böhringer, T. Büttner, and M. Kraus. Economic effects of VAT reforms in Germany. Applied Economics, 42(17):2165-2182, 2010. 
S. R. Bond and M. P. Devereux. On the design of a neutral business tax under uncertainty. Journal of Public Economics, 58(1):57-71, 1995.

R. J. Caballero and A. Simsek. A model of endogenous risk intolerance and LSAPs: Asset prices and aggregate demand in a "Covid-19" shock. The Review of Financial Studies, 34(11):5522-5580, 2021.

P. Cahuc, S. Carcillo, and A. Zylberberg. Labor economics. MIT press, 2014.

L. Christiano, M. Eichenbaum, and C. Evans. Nominal rigidities and the dynamic effects of a shock to monetary policy. Journal of Political Economy, 113(1):1-45, oct 2005.

R. Cooper and J. L. Willis. The cost of labor adjustment: Inferences from the gap. Review of Economic Dynamics, 12(4):632-647, 2009.

R. De Mooij and M. P. Devereux. An applied analysis of ACE and CBIT reforms in the EU. International Tax and Public Finance, 18:93-120, 2011.

R. De Mooij, R. Fenochietto, S. Hebous, S. Leduc, and C. Osorio-Buitron. Tax policy for inclusive growth after the pandemic. IMF Fiscal Affairs, Special Series on Covid-19, 2021.

P. Engler, G. Ganelli, J. Tervala, and S. Voigts. Fiscal devaluation in a Monetary Union. IMF Economic Review, 65(2):241-272, 2017.

European Parliament. The EU framework for fiscal policies, 2021. URL https://www . europarl . europa.eu/factsheets/en/sheet/89/the-eu-frameworkfor-fiscal-policies.

Eurostat. National accounts (including GDP and regional accounts) - Overview, 2021. URL https://ec.europa.eu/eurostat/web/national-accounts.

E. Farhi, G. Gopinath, and O. Itskhoki. Fiscal devaluations. Review of Economic Studies, $81(2): 725-760,2014$.

J. Galí. Monetary policy and bubbles in a new keynesian model with overlapping generations. American Economic Journal: Macroeconomics, 13(2):121-167, 2021.

M. Gertler. Government debt and social security in a life-cycle economy. CarnegieRochester Conference Series on Public Policy, 50:61-110, 1999.

P. Gottfried and W. Wiegard. Exemption versus zero rating: A hidden problem of VAT. Journal of Public Economics, 46(3):307-328, 1991.

V. Gregory, G. Menzio, and D. G. Wiczer. Pandemic recession: L or V-shaped? NBER Working Paper Series, No 27105, 2020.

B. Groom and D. P. Maddison. New estimates of the elasticity of marginal utility for the UK. Environmental and Resource Economics, 72(4):1155-1182, 2019. 
C. Groth and H. Khan. Investment adjustment costs: An empirical assessment. Journal of Money, Credit and Banking, 42(8):1469-1494, 2010.

J. D. Hamilton. Why you should never use the Hodrick-Prescott filter. Review of Economics and Statistics, 100(5):831-843, 2018.

S. Hebous and M. Ruf. Evaluating the effects of ACE systems on multinational debt financing and investment. Journal of Public Economics, 156:131-149, 2017.

B. J. Heijdra. Fiscal policy multipliers: The role of monopolistic competition, scale economies, and intertemporal substitution in labour supply. International Economic Review, 39:659, 1998.

Institute for Fiscal Studies and J. Mirrlees, editors. Tax by design: The Mirrlees Review. Oxford University Press, 2011.

C. Jaag, C. Keuschnigg, and M. Keuschnigg. Pension reform, retirement, and life-cycle unemployment. International Tax and Public Finance, 17(5):556-585, 2010.

Ò. Jordà, K. Knoll, D. Kuvshinov, M. Schularick, and A. M. Taylor. The rate of return on everything, 1870-2015. The Quarterly Journal of Economics, 134(3):1225-1298, 2019.

G. Kaplan, B. Moll, and G. L. Violante. The great lockdown and the big stimulus: Tracing the pandemic possibility frontier for the US. NBER Working Paper Series, No. 27794, 2020 .

C. Keuschnigg and M. Keuschnigg. Transition strategies in enacting fundamental tax reform. National Tax Journal, 65(2):357-385, 2012.

D. Krueger, H. Uhlig, and T. Xie. Macroeconomic dynamics and reallocation in an epidemic: Evaluating the "swedish solution". NBER Working Paper Series, No. 27047, 2020.

A. T. Levin, A. Onatski, J. C. Williams, and N. Williams. Monetary policy under uncertainty in micro-founded macroeconometric models. NBER macroeconomics annual, 20: 229-287, 2005.

L. Liu, B. Lockwood, M. Almunia, and E. H. Tam. VAT notches, voluntary registration, and bunching: theory and U.K. evidence. Review of Economics and Statistics, 103: 151-164, 2021.

OECD. Pensions at a glance, 2021a. URL https://stats.oecd.org/Index.aspx? DataSetCode=PAG.

OECD. Net replacement rate in unemployment, 2021b. URL https://stats . oecd.org/ Index $\cdot$ aspx ?DataSetCode=NRR.

J. Pfeifer. A guide to specifying observation equations for the estimation of DSGE models. Research series, pages 1-150, 2014. 
C. D. Romer and D. H. Romer. The macroeconomic effects of tax changes: estimates based on a new measure of fiscal shocks. American Economic Review, 100(3):763-801, 2010 .

Statistik Austria. Input-Output Table 2017, 2021a. URL https://www.statistik. at/web_en/statistics/Economy/national_accounts/input_output_statistics/ index.html.

Statistik Austria. Public finance, 2021b. URL https://www.statistik.at/web_en/ statistics/Economy/Public_finance_taxes/public_finance/index.html.

Statistik Austria. Pensionseinkommen in der gesetzlichen Pensionsversicherung im Dezember 2019, 2021c. URL https://www.statistik.at/web_de/statistiken/menschen_ und_gesellschaft/soziales/gender-statistik/pensionen/075959.html.

Statistik Austria. Labour market, 2021d. URL https://www.statistik.at/web_en/ statistics/PeopleSociety/labour_market/index.html.

C. Whalen and F. Reichling. Estimates of the Frisch elasticity of labor supply: a review. Eastern Economic Journal, 43(1):37-42, 2017. 